\title{
Meraviglia und admiratio in den Stanze und den Silvae Angelo Polizianos
}

\subsection{Biografische Notizen}

Angelo Poliziano wurde 1454 in Montepulciano bei Florenz geboren. Schon früh begann er, Gedichte in Griechisch und Lateinisch zu verfassen und Übersetzungen aus dem Griechischen anzufertigen. Unter anderem übersetzte er vier Bücher der Ilias, ${ }^{1}$ womit er die Aufmerksamkeit Lorenzo de’ Medicis erlangte. Nach seinem Studium wurde er zu dessen Kanzler, ebenfalls trug Lorenzo ihm die Erziehung seiner beiden Söhne - Piero und Giovanni - auf. Sein Poem Stanze cominciate per la giostra del Magnifico Giuliano di Piero de' Medici - eine ins Mythologische erhobene Lobrede auf die Medici ${ }^{2}$ - gehört heute zu den Klassikern der italienischen Literatur. Poliziano begann 1475 mit der Abfassung, das Werk blieb jedoch unvollendet, nachdem Giuliano de' Medici 1478 in der Congiura de' Pazzi ermordet wurde. Nach Streitigkeiten mit Clarice Orsini weilte Poliziano einige Jahre ausserhalb von Florenz, vornehmlich in Mantua und Venedig. 1480 rief Lorenzo ihn nach Florenz zurück, wo er unter anderem als Gesandter der Stadt mit Papst Innozenz VIII. diplomatische Gespräche tätigte. 1480 erhielt er am Studio Fiorentino den Lehrstuhl für griechische und lateinische Literatur. ${ }^{3}$

Poliziano hat zahlreiche philosophische, philologische und literarische Schriften verfasst und gehört zu den produktivsten wie auch kreativsten Gelehrten seiner Zeit. Er war einflussreiches Mitglied des kulturellen Zirkels rund um Lorenzo de' Medici, dem unter anderem auch Persönlichkeiten wie Marsilio Ficino oder Cristoforo Landino angehörten. Poliziano hat entscheidend zur Wiederentdeckung und Verbreitung antiker griechischer Schriften beigetragen. Er war eine der ersten Personen, die eine Kopie von

1 Poliziano übersetzte in den Jahren 1470-1475 das zweite, dritte, vierte und fünfte Buch der Ilias. Siehe Alice Levine Rubinstein, Imitation and Style in Angelo Poliziano's Iliad Translation, in: Renaissance Quarterly 36 (1983), S. 48.

2 Asor Rosa spricht von einer fabelhaften und raffinierten Traumwelt, die sich durch verzaubertes Staunen («incantato stupore») auszeichnet: Alberto Asor RosA, Storia europea della letteraura italiana. I. Le origini e il Rinascimento, Torino 2009, S. 416.

3 Отto Schönberger, Einleitung, in: Angelo Poliziano, Rusticus, Einleitung, Text, erste deutsche Übersetzung und Anmerkungen von Otto Schönberger, Würzburg 1992, S. 11. 
Aristoteles' Poetik besassen, und hat sich mit zunehmendem Alter vertieft mit den Schriften des Aristoteles auseinandergesetzt. Bezüge zur aristotelischen Poetik sind in den untersuchten Werken Polizianos allerdings nur ansatzweise präsent, ${ }^{4}$ und während Aristoteles der Dichtung einen rationalen Wert absprach, begründete Poliziano die ursprüngliche Form der Erkenntnis in der Dichtung. 5

Für meine Recherche nach der Poetik und Ästhetik des Staunens gehe ich im Folgenden auf zwei Texte vertieft ein: zum einen auf die Stanze cominciate per la giostra del Magnifico Giuliano di Piero de' Medici, weil sie im neuplatonisch geprägten florentinischen Umfeld eine eigenständige ästhetische Position markieren. ${ }^{6}$ Zum anderen werde ich drei der Silvae (Manto, Ambra, Nutricia) analysieren, ${ }^{7}$ die als Vorlesungseinführungen konzipiert sind und in denen

4 Vittore Branca sieht in Polizianos literarischen Werken, die ab 1480 entstanden sind, starke Einflüsse der aristotelischen Poetik. So greife Poliziano in Manto (Vv. 339 ff.) und Nutricia (Vv. 74 ff.) die Universalität der Dichtung auf und konzipiere an verschiedenen Stellen die Dichtung als imitatio der Natur. Ebenso betone Poliziano genauso wie Aristoteles den pädagogischen und zivilisatorischen Charakter der Dichtung. In Bezug auf den ersten Punkt nennt Branca selbst, dass Poliziano zugleich den furor divinus prominent einbinde - ein Element, das bei Aristoteles inexistent ist. Analog kann man zur imitatio hinzufügen, dass Poliziano diese nicht in einem aristotelischen Sinne versteht: Es geht nicht um die Nachahmung menschlicher Handlungen, sondern um die Nachahmung der Vielfalt der Natur. Die Handlung als poetisches Element hat höchstens in den Stanze ein gewisses Gewicht, diese sind aber vor Polizianos Lektüre von Aristoteles' Poetik entstanden. Auch der dritte Punkt - die pädagogisch-zivilisatorische Funktion der Dichtung, bindet Poliziano anders ein als Aristoteles. Poliziano begründet die Zivilisationskraft mythopoetisch und eingebunden in einen göttlichen Kontext, anders als Aristoteles also, der die zivilisatorische Wirkung an die moralische Aussagekraft der Handlung bindet. Vgl. dazu Vittore Branca, Umanesimo della parola tra poesia, filologia, filosofia e scoperta della Poetica aristotelica, in: Ders., Poliziano e l'umanesimo della parola, Torino 1983, S. 15.

5 Aguzzi-Barbagli, Humanism and Poetics, S. 85, 97. Für Aristoteles hat Dichtung einen moralisch-ethischen, nicht aber einen erkenntnistheoretischen Wert. So sind Mythen der metaphysischen Erklärung entgegengesetzt, wenn auch beide aus dem Staunen hervorgehen. Siehe Aristoteles, Metaphysik. Schriften zur ersten Philosophie, übersetzt und herausgegeben von Franz F. Schwarz, Stuttgart 2010, 982b. Die aristotelische Metaphysik wird in der Folge mit Met. wiedergegeben.

6 Diese Position resultiert insbesondere daraus, dass Poliziano das Staunen nicht auf das Göttliche, sondern im Laufe der Stanze immer konzentrierter auf die Kunst und die Dichtung lenkt.

7 Ich werde die vierte Silva Rusticus nicht vertieft behandeln. Rusticus ist zwar - analog zu Vergils Georgica - eine Metapher der poetischen Kreation, fokussiert aber vornehmlich auf die Invention und die Mnemotechnik und ist kaum auf die Wirkung ausgerichtet. Das Staunen, insbesondere die admiratio, spielt deshalb keine grosse Rolle. Eine reichhaltige Analyse von Rusticus mit dem Fokus auf memoria bietet Émilie Séris, Les étoiles de Némésis. La rhétorique de la mémoire dans la poésie d'Ange Politien (1454-1494), Genève 2002. 
die Poetik Polizianos anhand einer kreativen Form der imitatio, die aus dem Staunen kommt und zum Staunen führt, zum Ausdruck kommt.

\subsection{Kontext der Forschung}

Polizianos Werk wurde lange Zeit zweigeteilt in eine «jugendliche» Phase der volkssprachlichen Poesie und eine zweite, spätere Phase der Philologie, die ausschliesslich dem Studium der antiken Texte gewidmet gewesen sei. ${ }^{8}$ Vittore Branca hat gezeigt, dass diese Zweiteilung zu kurz greift und das literarische Schaffen Angelo Polizianos dieser Kategorisierung nur bedingt entspricht. Dennoch löst Branca die Zweiteilung nicht auf, sondern überschreibt die linguistischen Kriterien - volkssprachliche Poesie versus lateinische Philologie - mit philosophischen Kategorien: Er definiert die erste, jugendliche Phase als platonische, die spätere als aristotelische. ${ }^{9}$ Erstere zeichne sich als mystisch-hermetische Phase des furor poeticus und des jugendlichen Enthusiasmus aus, letztere als rationalistische, der präzisen Sprachanalyse gewidmete. ${ }^{10}$ Allerdings widerstreben sowohl die Stanze, gemeinhin der früheren Phase zugeordnet, als auch die Silvae, der späteren Phase angehörend, der linguistischen wie auch der philosophischen Zweiteilung.

Die Stanze sind in einem neuplatonischen Umfeld entstanden, entsprechend ist die zentrale Allegorie des Werkes gestaltet: «Iulio [...] viene avviato alla difficile e dolorosa strada della perfezione, che, dalla cerva dei sensi, lo conduce alla Simonetta della virtù. ${ }^{11}$ Allerdings wird diese leicht zu entziffernde Allegorie mehr und mehr von zeitgenössischen Kunstdiskursen überlagert - etwa demjenigen über die Ähnlichkeit der Kunst zur Natur -, die ohne theologische Komponente auskommen. ${ }^{12}$ Entgegen der Aussage, die frühe Phase zeichne sich durch eine oberflächliche Stilisierung der Sprache

8 Branca, Umanesimo della parola, S. 3.

9 Diese Wende wird gemeinhin um 1480 herum angesiedelt, nach der Congiura de' Pazzi und somit zusammen mit dem schwindenden Traum von der italienischen Republik und ebenfalls nach der Trennung von Lorenzo de' Medici aus bisher unerklärten Gründen. Es darf allerdings nicht vergessen werden, dass dies nur ein temporärer Bruch mit den Medici darstellt und Poliziano wieder nach Florenz zurückgekehrt ist. Siehe ebd., S. 3, 13.

10 Branca, Umanesimo della parola, S. 11.

11 Davide Puccini, Introduzione, in: Poliziano, Stanze. Orfeo. Rime, S. XLVII. Puccini zitiert Martelli, ohne genaue bibliographische Angaben zu nennen. Siehe ANGelo Poliziano, Stanze cominciate per la Giostra di Giuliano de' Medici, a cura di Mario Martelli, Alpignano 1979.

12 Ebenso spricht die Tatsache, dass Iulios Aufstieg nicht vollendet wird, für einen Bruch mit der Idee des ascensus - sowohl in der ästhetischen als auch in der politischen Leseweise. 
aus, ${ }^{13}$ begegnen wir bereits in den Stanze einer reflektierten ästhetischen Position, einer kreativen Überlagerung von mythologischem, symbolischem und enkomiastischem Diskurs sowie einer Collage aus unzähligen intertextuellen Verweisen, die von einer intensiven Auseinandersetzung mit den antiken und zeitgenössischen Dichtern zeugen.

Die Silvae zeugen eindeutig vom bestehenden Interesse an der Dichtung sowie der anhaltenden Aktualität platonischer Konzepte. ${ }^{14}$ Insbesondere die Funktions- und Wirkungsweisen des furor poeticus werden in den Silvae im Gegensatz zu den Stanze - explizit ausgeführt. ${ }^{15}$ Ebenso sind die Silvae weit davon entfernt, sich einer realitätsgetreuen Nachahmung verschrieben und vom symbolisch-allusiven, synthetischen Stil gelöst zu haben - beides wurde so von Branca postuliert. ${ }^{16}$ In den Silvae begegnen wir einer gleichzeitig punktuellen und universellen Auseinandersetzung mit der Dichtung und müssen nicht auf elegante literarische Stilistik verzichten. Auch wenn es sich um Vorlesungseinführungen handelt, sind die Silvae alles andere als eine rigorose philologische Analyse, und obwohl sie von der tiefgreifenden Kenntnis der behandelten Texte zeugen, handelt es sich vielmehr um ein Zelebrieren der Poeten und der Poesie, einen « Kult» bzw. eine «rituelle Hommage », die an die «Sakralität des poetischen Aktes » erinnert. ${ }^{17}$ So hat denn auch Bausi richtig erkannt, dass es gerade die Silvae sind, die sich einer eindeutigen Kategorisierung entziehen, da sie zwar alle Bereiche von Polizianos Schaffen tangieren, sich aber weder an die volkssprachliche Poesie der jungen Jahre

13 Weitere Kritiker dieser These sind Atтılio Manzi, La mitologizzazione del testo letterario: le Stanze del Poliziano, in: Quaderns d'Italià 13 (2008), S. 128; Attilio Betrinzoli, Daedalum iter. Studi sulla poesia e la poetica di Angelo Poliziano, Firenze 1985, S. 69; Asor RosA, Storia europea della letteratura italiana, S. 411-412.

14 Greenfield, Humanist and Scholastic Poetics, S. 257, 261.

15 Bettinzoli, Daedalum iter, S. 87. Die Idee göttlicher Inspiration widerspricht den aristotelischen Konzepten der Mimesis und des Wahrscheinlichen. Siehe AguzzIBARBAgli, Humanism and Poetics, S. 121.

16 Branca, Umanesimo della parola, S. 15, Fn. 43. Branca spricht auch davon, Poliziano habe sich gegen Ende der 148oer-Jahre einem « dettato nudo e disadorno, aderente alla realtà, anche alle più umili e degradate » zugewandt, muss dann aber selbst eingestehen, dass dennoch die metaphorische, allusive und evokative Sprache Polizianos, wie wir sie aus seinen früheren Werken kennen, noch immer präsent ist. Es ist kaum vorstellbar, dass Poliziano in seinen späten Jahren von seinen Prinzipien der Vielfalt, der Collage und der Synthese abgewichen ist; ganz sicher gilt dies für die Silvae (noch) nicht. Brancas Aussagen dürften für einzelne Werke wie zum Beispiel Kommentare aristotelischer Schriften zutreffen, sind aber nicht für seine gesamte literarische Produktion zu verallgemeinern. Siehe ebd., S. 21. 
anschliessen noch den fachlichen Tätigkeitsbereichen Polizianos - der Philologie, der Literaturkritik und der Pädagogik - eindeutig zuordnen lassen. ${ }^{18}$

The Sylvae show the continuity and mutual interdependence between poetry, philology and pedagogy in Poliziano's work. ${ }^{19}$

Eigenständigkeit und Vielfältigkeit in allen literarischen Belangen sind nicht zuletzt die dominierenden Charakteristika von Polizianos gesamtem Werk.

Teil dieser Eigenständigkeit ist ein ausgeprägter Eklektizismus. Die kreative Anbindung an verschiedene Texte und Traditionen - in der Form von Zitaten, Analogien, Metaphern, kreativen Paraphrasen und literarischem Synkretismus - ist bezeichnend für Polizianos Schaffensweise. Thomas Greene geht sogar so weit, die « real substance of the poem » als «a tissue of subtexts » zu bezeichnen..$^{20}$ Die vielschichtigen Anspielungen sind von der Oberfläche bis in immer neue Tiefen zu entdecken, was im Leser zum einen Erstaunen wenn neue Bezüge entdeckt werden - und zum anderen Bewunderung - für die enorme Gelehrtheit Polizianos - auslöst.

Der Eklektizismus ist aber nicht nur Ausdruck der Gelehrtheit Polizianos, sondern unterstützt die wenig normierte Form der Silva und unterläuft allegorische, moralisch-ethische Deutung.

[...] he works with the same notion of the silva in the Miscellanea and in the Sylvae, a , disorder' which might be related to the absence of allegorical organisation of material that presents it as ,universal.

In place of universality claimed for material arranged allegorically, Poliziano emphasises the variety - varietas - of his work. ${ }^{21}$

\subsection{Die Stanze}

Die Stanze zählen zum Frühwerk Polizianos und wurden in volgare verfasst. ${ }^{22}$ Sie können in einem weiten Sinne den Genres des klassischen Epos, der

18 Francesco Bausi, Introduzione, in: Poliziano, Silvae, S. XXX.

19 Claire E. L. Guest, Varietas, poikilia and the silva in Poliziano, in: Hermathena 183 (2007), S. 14.

20 Thomas M. Greene, The Light in Troy. Imitation and Discovery in Renaissance Poetry, New Haven / London 1982, S. 158.

21 Guest, Varietas, S. 18.

22 Polizianos stanza, auch ottava rima genannt, ist eine Strophenform, die sich aus acht elfsilbigen Versen im Reimschema abababcc zusammensetzt. Die Stanzen wurde später berühmt durch die Epen Ariostos und Tassos, im Deutschen insbesondere durch Goethes Faust. Floriana Calitti beschreibt in ihrer Storia dell'ottava rima nel Rinascimento den 
Liebeslyrik, der höfischen Literatur sowie des Triumphgedichts zugeordnet werden. ${ }^{23}$ Der Titel nimmt Bezug auf das Genre der giostra, des epischen Turniergedichts, wie insbesondere Luigi Pulci es geprägt hat - die Stanze verzeichnen aber einen weitaus freieren, stilistisch erhöhten und vor allem stärker mythologischen, auf die Lobrede zielenden Charakter. ${ }^{24}$ Die Stanze können auch deshalb nur bedingt zum Genre der giostra gezählt werden, weil das eigentliche Turnier gar nicht beschrieben wird: Das erste Buch erzählt in 125 Stanzen die Vorgeschichte - das innamoramento -, das Turnier wird nur in der eröffnenden Strophe erwähnt; erst das zweite Buch erzählt in 46 Stanzen von einem Traum, der zur giostra aufruft und zum ruhmvollen Kampf für die Liebe inspiriert. Nach diesen 46 Stanzen endet das Werk abrupt, höchstwahrscheinlich ist es Fragment geblieben, nachdem Giuliano de' Medici - die mythologisierte Hauptfigur der Stanze - in der Congiura de' Pazzi ermordet wurde.

Tant par leur structure compartimentée et fragmentaire que par l'élaboration particulière de la matière les Stanze de Politien échappent donc à toute étiquette. $^{25}$

Die Stanze weisen eine klare Handlungslinie auf, die von Ida Maïer wie folgt zusammengefasst wird:

En apparence l'histoire narrée par Politien est simple. Pour justifier la participation victorieuse de Julien de Médicis au tournoi de 1475 , l'auteur prête à son héros les traits du jeune Julio qui méprise l'amour et ne connaît d'autre plaisir que la chasse. Erôs dépité jure de se venger : au cours d'une partie de chasse il

gleichzeitig lyrischen und narrativen Charakter von Polizianos stanza und vergleicht sie mit weiteren Autoren, darunter Giovanni Boccaccio und Pietro Bembo. Siehe Floriana CAlitti, Fra lirica e narrativa. Storia dell'ottava rima nel Rinascimento, Firenze 2004, S. XII ff.

23 IDA MAÏER, Ange Politien. La formation d'un poète humaniste (1469-1480), Genève 1966, S. 284. Zum Genre des Triumphes siehe Christina Storey, The Philosopher, the Poet, and the Fragment: Ficino, Poliziano, and Le stanze per la giostra, in: The Modern Language Review 98 (2003), S. 6o9.

24 Davide Puccini, Angelo Poliziano. Profilo storico-critico dell'autore e dell'opera, in: Poliziano, Stanze. Orfeo. Rime, S. XLIII-XLIV. Siehe ebenfalls MaÏer, Ange Politien, S. 275: «L'idée d'exploiter un événement pseudo-guerrier pour en faire le sujet d'un poème d'allure épique était bien conforme à l'esprit des milieux courtisans de l'époque. [...] Le schéma était assez constant: on décrivait le cortège, le combat, la distribution du prix. [...] la transformation de ce matériel en poème capable de se suffire exigeait une véritable création et l'invention d'un nouveau schéma et de nouveaux critères: c'est ce que fit Politien. »

25 MAÏER, Ange Politien, S. 284. 
entraîne Julio à la poursuite d'une biche fictive qui disparaît soudain pour faire place à l'apparition d'une splendide jeune femme, Simonetta; le héros tombe alors passionnément amoureux. L’Amour s'apprête à rejoindre l'île de Chypre, royaume de Vénus - longuement décrit -, pour aller raconter son exploit. La déesse se réjouit de la victoire de son fils et décide de mettre Julio à l'épreuve en lui inspirant au cours d'un songe, la volonté d'entrer en lice pour l'amour de sa dame. ${ }^{26}$

Die diegetische Ebene ist unterlegt von einer Textcollage aus unzähligen intertextuellen Verweisen auf antike und zeitgenössische Texte. ${ }^{27}$ Zudem beinhaltet sie eine ästhetische Reflexion, die insbesondere den Bildcharakter der Poesie als auch ihren enkomiastischen Wert umschliesst.

Wird das Poem extradiegetisch vom Wunsch, die Medici zu ehren, animiert, ist es intradiegetisch Amor, der die Fäden zieht und die Handlung vorantreibt. Für beide „Erzählursachen“ spielt das Staunen eine tragende Rolle.

Die Familie der Medici erfüllt im Gedicht mehrere Funktionen gleichzeitig. Sie ist Auftraggeberin und Inspiration des Gedichts:

1. Die bewundernswerten Taten ihrer Mitglieder regen zur Dichtung an.

2. Sie stellt das zentrale Motiv sowie die Hauptfigur, die über die Verlagerung ins Mythologische zusätzliche Steigerung erfährt: Das Turnier bzw. sein Sieger Giuliano de' Medici werden in der Dichtung gefeiert, um verewigt zu werden. ${ }^{28}$

3. Durch die poetische Darstellung, die das Staunenswerte hervorhebt, sollen auch die Zuhörer in Staunen und Lob der Familie verfallen - das Gedicht hat neben seiner literarischen Ambition auch einen politischen Zweck.

Explizit finden wir das Lob der Medici zu Beginn des ersten wie auch des zweiten Buches.

L'antica gloria e 'l celebrato onore chi non sa della Medica famiglia, e del gran Cosmo, italico splendore, di cui la patria sua si chiamò figlia? e quanto Petro al paterno valore

26 Ebd., S. 288.

27 Siehe dazu die ausführlich kommentierten Ausgaben von Davide Puccini oder von Stefano Carrai. Zu den wichtigsten Quellen zählen die Werke von Vergil, Lukrez, Statius, Horaz, Claudian, Ovid, Homer, Apollonios von Rhodos, Dante, Boccaccio, Petrarca, Pulci und Lorenzo de' Medici sowie Polizianos eigene Texte.

28 Maria Luisa Doglio, Metamorfosi, simbolo e favola. Per una lettura delle «Stanze» del Poliziano, in: Italianistica 12 (1983), S. 198. 
n'aggiunse pregio, e con qual maraviglia

dal corpo di sua patria rimosse abbia

le scelerate man, la crudel rabbia? ${ }^{29}$ (II, 3 )

Die Mitglieder der Familie - an dieser Stelle Cosimo und Piero de' Medici werden als brillante Staatsmänner und väterliche Führungsfiguren dargestellt, wobei vor allem die antike Glorie sowie der Schutz der «patria» hervorgehoben werden. Der Gestus des Lobes, der Bewunderung und teilweise gar der Begeisterung für die „Helden“ der Familie Medici spiegelt sich auch in der Sprache wider. Thomas Greene hat gezeigt, dass sich die Stanze - trotz eklektischem Grundschema - vorwiegend an der Sprache von Petrarcas Trionfi orientieren. ${ }^{30}$

Genauso triumphierend, wenn auch auf spielerischere Weise, initiiert Amor das innamoramento von Iulio für Simonetta als Racheakt für Iulios Gleichgültigkeit gegenüber der Liebe. Wir begegnen Iulio bei der Jagd, wobei er dem Leser als zu bestaunendes Objekt vorgestellt wird: «Ah quanto a mirar Iulio è fera cosa. » $(\mathrm{I}, 33, \mathrm{~V} .1)^{31}$ « [F]era cosa » bezieht sich grammatisch nicht auf Iulio, sondern auf «mirar ». Die Charakteristik des Helden („essere fiero“) wird auf den Leser und Betrachter übertragen, gleichzeitig kommt dem Helden die Rolle des Betrachters zu: Nachdem der Liebespfeil sein Ziel erreicht hat, nimmt das innamoramento seinen Lauf vornehmlich über das Sehen (mirare). Mirare weist verschiedene Bedeutungen auf: „zielen/streben nach etwas“, „beobachten, aufmerksam betrachten, bewundernd anschauen“ sowie „erstaunt/überrascht sein“. ${ }^{32}$ Alle drei Bedeutungen spielen für das Gedicht

29 Ich zitiere aus folgender Ausgabe: Angelo Poliziano, Stanze. Orfeo. Rime, introduzione, note e indici di Davide Puccini, Milano 2010. Die deutschen Übersetzungen der Stanze stammen aus: Angelo Poliziano, Der Triumph Cupidos. «Stanze», übertragen und eingeleitet von Emil Staiger, Zürich 1974: «WER kennt ihn nicht, den hochgeehrten Namen, / Den alten Ruhm des Hauses Medici, / Des großen Cosmo, der Italiens Glanz war, / Des Vaterstadt sich seine Tochter nannte? / Wer weiß nicht, was dem Wert des Vaters Petro / Hinzugefügt und wie er zum Erstaunen / Vom Körper seiner Stadt die arge Wut, / Die frevelhaften Hände weggestossen? »

30 GreEne, The Light in Troy, S. 156.

31 WIE herrlich ist es, Julio zuzuschauen. // Staiger übersetzt «fera cosa» mit «herrlich», wobei "fero“ gängigerweise eher entweder „würdevoll, kühn, sicher“ oder aber „schrecklich, erschreckend, grausam“ bedeutet. Ich hätte gesagt, dass sich an dieser Stelle die Kühnheit des Jägers, die in der vorangehenden Stanza beschrieben wird, auf den Zuschauenden überträgt.

32 http://www.garzantilinguistica.it/ricerca/?q=mirare (Stand April 2021). Diese Bedeutungsvarianten von "mirare“ lassen sich auch historisch belegen, siehe dazu www. tommaseobellini.it/. 
insgesamt, insbesondere aber für den Verlauf des innamoramento eine entscheidende Rolle und gipfeln schliesslich im Staunen (maraviglia).

Quasi aus dem Nichts (I, 34, V.1) schafft Amor das Bild einer stolzen, schönen Hirschkuh ( «l'imagin d'una cervia altera e bella », I, 34, V. 2), ${ }^{33}$ an deren Fersen sich Iulio unmittelbar heftet. Der schöpferische Aspekt Amors wird betont, der Bildcharakter dominiert («imagin», « effigie»). Was sich Iulio initial als leichte Beute präsentiert, wird zum unerreichbaren «Scheingebilde» (I, 36 , V. 1). Schliesslich erreicht er eine Lichtung, auf der eine verschleierte Nymphe erscheint («apparve»), während die Hirschkuh verschwindet («sparve», I, 37, Vv. 7-8). Iulios Aufmerksamkeit richtet sich jetzt ganz auf die Nymphe, deren Gestalt (« figura ») er voller Staunen (« tutto ripien di maraviglia », I, 38, V. 5) betrachtet. Maria Luisa Doglio sieht an dieser Stelle - in der Abwendung Iulios von der Jagd hin zur « estatica meraviglia », mit der er die junge Frau betrachtet - ein zentrales fiabeskes Moment der Metamorphose am Werk, das die Stanze insgesamt kennzeichnet. ${ }^{34}$

Simonetta transformiert nicht nur Iulio (I, 38), sondern die gesamte Umgebung: Der Wald lächelt ihr zu und mit einer leichten Bewegung der Augenbraue beruhigt sie die stürmischen Winde (I, 43). Wenn sie die Lichtung verlässt, klagen die Bäume und weinen die Vögel. Die Gräser und Kräuter verwandeln sich unter ihren Schritten in eine Fülle verschiedener Farben $(I, 55){ }^{35}$

[...] elle [Simonetta Cattaneo] est cette créature miraculeuse dont la présence et les paroles ont le magique pouvoir d'apaiser la nature et de la transformer comme par enchantement $[\ldots]^{36}$

Simonettas Augen beleuchten als «Liebeslichter » die Umgebung: Alles, was von diesem Licht getroffen wird, wird lieblich und anmutig (I, 44). Mit ihrem Lächeln kann Simonetta Berge versetzen, den Lauf der Sonne anhalten, das Paradies eröffnen. Mit ihren Worten, die sanft, weise und lieblich sind, könnte sie Marmor zerteilen und sogar eine Sirene verliebt machen.

Volta la ninfa al suon delle parole,

lampeggiò d'un sì dolce e vago riso, che i monti avre' fatto ir, restare al sole, che ben parve s'aprissi un paradiso.

33 UND schuf mit seiner Hand aus leichter Luft / Das edle, schöne Bildnis einer Hindin.

34 Doglio, Metamorfosi, simbolo efavola, S. 207. Vgl. dazu auch MAÏE R, Ange Politien, S. 315.

35 In Hesiods Theogonie ist es Aphrodite, welche die Gräser unter ihren Füssen erblühen lässt. Siehe Hesıod, Théogonie - Les Travaux et les Jours - Le Bouclier, texte établit et traduit par Paul Mazon, Paris 1986, Vv. 193-195.

36 MaÏ̈ R, Ange Politien, S. 318. 
Poi formò voce fra perle e vïole, tal ch'un marmo per mezo avre' diviso; soave, saggia e di dolcezza piena, da innamorar non ch'altri una Sirena: ${ }^{37}\left(I, 5^{\circ}\right)$

Die Mimik und Sprache Simonettas, die gleichsam auch jene Amors sind, entfalten eine wundersame Wirkung auf die Umgebung, wie es sonst nur Orpheus' Gesang nachgesagt wird (vgl. Manto, Praefatio). Die schöpferische Kraft Orpheus', der mit seinem Gesang nicht nur Menschen, Tiere, Pflanzen und Berge in Staunen versetzt, sondern der auch die Menschen zivilisiert und als theologus poeta die geheimnisvollen Prinzipien des Kosmos zelebriert, wird in den Stanze Amor und - durch Amor - Simonetta zugeschrieben. ${ }^{38}$ Gleichzeitig gleicht ihre Beschreibung jener von Venus - insbesondere in den Topoi der Schönheit -, ohne dass ihre Figur die historische oder literarische Eigenständigkeit verliert.

Mit Iulios Staunen über Simonetta wird bewusst gespielt, wenn es auf der einen Seite durch die Nennung ihrer bürgerlichen Herkunft geschwächt (I, 51), auf der anderen Seite durch die Abstammung von Venus gesteigert wird.

meraviglia di mie bellezze tenere

non prender già, ch'io nacqui in grembo a Venere. ${ }^{39}$ (I, 53, Vv. 7-8)

Die explizite Aufforderung zum „Nicht-Staunen-Müssen“ verfolgt den Zweck, Staunen auszulösen - bei der Figur und den Lesern gleichermassen. ${ }^{40}$

Als Simonetta den prato verlässt, um in die Stadt zurückzukehren, bleibt Iulio versteinert zurück. Die Versteinerung erinnert an den Mythos der Medusa und ist Ausdruck der Erstarrung - verdeutlicht in der Wiederholung von « sta » im Gegensatz zu Simonettas « andar »:41

37 Die Nymphe, hingewandt dem Klang der Worte, / Erstrahlte von so reizend-mildem Lächeln: / Die Berge hätte es verrückt, die Sonne / Gebannt. Ein Paradies schien aufzugehen. / Dann bildete sie Laute zwischen Perlen / Und Nelken, einen Stein entzweizuspalten, / So wohlgesittet, so von Milde strömend: / Sirenen hätten anders nicht betört.

38 John Warden, Orpheus and Ficino, in: Ders. (Hg.), Orpheus. The Metamorphoses of a Myth, Toronto 1982, S. 93. Siehe ebenso Greene, The Light in Troy, S. 162.

39 Ob meiner zarten Schönheit wundre länger / Dich nicht: In Venus' Schoß bin ich geboren.

40 Mario Martelli, Simbolo e struttura delle Stanze, in: Poliziano, Stanze cominciate per la Giostra, S. 93 .

41 Im zweiten Buch wird Minerva - in den Stanze als « vergine santa » bezeichnet - von Iulio zur Stärkung und Inspiration aufgerufen. Auf den Waffen der Minerva erblickt Iulio das 
sta come un forsennato, e 'l cor gli assidera, e gli s'aghiaccia il sangue entro le vene;

sta come un marmo fisso, e pur considera lei che sen va né pensa di sue pene, fra sé lodando il dolce andar celeste e 'l ventilar dell'angelica veste. ${ }^{42}\left(\mathrm{I}, 5^{6}, \mathrm{Vv} .3^{-8}\right)$

Nach dem Abgang Simonettas wechselt das Szenario abrupt zu Venus und der Darstellung ihrer Insel. Zuerst werden der Garten und der Palast beschrieben: Aus zwei Bächen fliessen die bittere und die süsse Flüssigkeit der Liebe zusammen, womit das Glück und das Leiden der Liebe veranschaulicht werden. In den Strom ergiessen sich die gegensätzlichen (Liebes-)Affekte wie Angst und Vergnügen oder Wut und Friedfertigkeit (I, 73-76). ${ }^{43}$ Die Beschaffenheit der Liebesinsel wird durch das Staunen charakterisiert, das - unter anderem - der Vielfalt der Düfte, Farben und Pflanzen entspringt:

Zefiro il prato con rugiada bagna, spargendolo di mille vaghi odori: ovunque vola, veste la campagna di rose, gigli, vïolette e fiori; l'erba di sue bellezza ha maraviglia, bianca, cilestra, pallida e vermiglia. ${ }^{44}\left(\mathrm{I}, 77, \mathrm{Vv} \cdot 3^{-8}\right)$

Die Pflanzen selbst sind erstaunt über ihre duftende und blühende Schönheit. Die Vielfalt von Flora und Fauna wird personifiziert ${ }^{45}$ - der Dichter lädt die Natur mit symbolischer und mythologischer Bedeutung auf -, was dem Leser eine ungewohnte Perspektive auf die natürliche Welt verschafft sowie die poetische unmittelbar mit der natürlichen Schöpfungskraft verbindet.

Bild von Simonetta, ebenso sieht er das Bild der Medusa, die Simonetta gegen die Liebe hat steinern werden lassen (I, 41-42).

42 Von Sinnen scheint er, ihm erstarrt das Herz. / Zu Eis gefriert das Blut in seinen Adern. / Reglos wie Marmor, schaut er ihr doch nach, / Die geht und sich um seinen Schmerz nicht kümmert, / Und preist für sich ihr himmlisch-zartes Schreiten / Und ihres engelgleichen Kleides Wehn.

43 Mit der Flüssigkeit werden anschliessend die Liebespfeile von Amor und seinen Gehilfen gefüllt.

44 Die Wiese badet Zephyros im Tau / Und schüttet tausend Ätherdüfte aus. / Wohin er fliegt, bekleidet er das Land / Mit Rosen, Lilien, Veilchen, Blütenzweigen. / Das Gras verwundert sich ob seiner Pracht / In Weiß und Blau und Blaß und Scharlachrot.

45 Die Rede ist unter anderem von Iacinto, Narcisso, Clizia, Adone, Croco und Acanto (I, 78-79). 
Die Beschreibung der Insel nimmt verstärkt magisch-wundersame Formen an, als die Leser zum Palast der Venus geführt werden. Dieser ist derart prächtig gestaltet, dass die Kunstfertigkeit alles übertrifft:

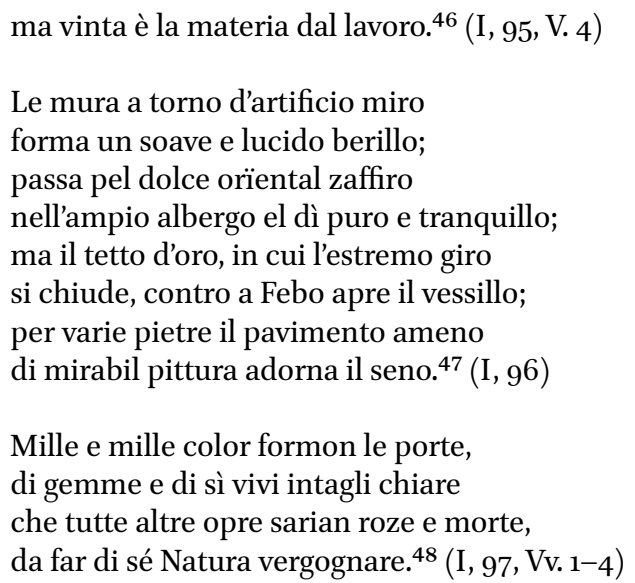

In Strophe 96 werden die Kunstfertigkeit wie auch die Kunstwerke als erstaunliche bezeichnet: «artificio miro » und «mirabil pittura» (I, 96, Vv. 1, 8). Die Doppelung der Begriffe im ersten und im letzten Vers bilden einen (Bilder-) Rahmen, sie umschliessen als Begriffe alle Formen der Kunst, die den Palast vom Dach bis hin zum Boden auskleiden.

Die ersten Darstellungen auf den Portalen sind an die Theogonie Hesiods angelehnt:49

Al prodigio del mistero cosmogonico [...] corrisponde il prodigio visibile e visualizzato del bassorilievo, dell'arte che imita la natura e la vince $[\ldots]^{50}$

Das Schöpferische, auf das Hesiods Theogonie sich bezieht, wird von Poliziano aufgenommen und ästhetisch umgesetzt: Die Entstehung der Welt wird zur

46 Den Stoff hat aber Kunstfleiß überwunden.

47 RINGS sind mit wunderbarer Kunst die Mauern / Gefügt aus lichtem, köstlichem Beryll. / Durch milden, östlichen Saphir dringt still / Und rein der Tag in die geräumige Wohnstatt. / Den höchsten Umkreis krönt ein goldnes Dach, / Das Phoebus sein Gezelt entgegenbreitet. / Im Reiz von bunten Steinen ziert der Boden / Mit wundervoller Schilderei das Innre.

48 In tausend Farben leuchten auf den Pforten / Juwelen und so wahres Meißelwerk, / Daß andre Kunst daneben roh und tot / Erschiene, ja Natur sich schämen würde.

49 Hesiod, Théogonie, Vv. 176-196. Vgl. dazu ebenfalls Maïer, Ange Politien, S. 325.

50 Doglio, Metamorfosi, simbolo e favola, S. 208. 
Entstehung der Kunst und der Literatur. Die Entstehung der Erde bzw. die Geburt der Venus wird auf drei Ebenen gleichzeitig dargestellt: der mythologischen, der gestalterischen im Relief sowie in der Erzählung des Dichters. Das Relief wird als derart echt («vero ») präsentiert (I, 100), ${ }^{51}$ dass Venus sogleich aus den Wellen zu steigen scheint (I, 101). ${ }^{2}$ Die Überlagerung von Realität, Kunst und Dichtung wird zum einen vom Erzähler explizit gemacht, zum anderen widerfährt sie dem Leser insofern, als er in die Ekphrasis des Reliefs eintaucht, sodass die Bildbeschreibung in den Hintergrund und die szenische Darstellung in den Vordergrund rückt (vgl. z. B. I, 101, Vv. 4-8). Dennoch wird die Differenz des Reliefs zur Wirklichkeit immer wieder bewusst zurückgeholt: Es ist, «als thronten » Venus und ihre Nymphen auf einer « Silberwolke», der Betrachter «glaubt» die Bewegung des Windes im festen und unbeweglichen Stein des Reliefs zu sehen (I, 103, Vv. 1-4).

Während der Betrachter verblüfft die Lebendigkeit des Reliefs zur Kenntnis nimmt, staunen die dargestellten Götter mit gerunzelter Stirn und hochgezogenen Brauenüber die Schönheit derVenus. In dieserSchönheit überlagern sich die mythologische Überlieferung und die künstlerische Darstellung.

Tutti gli dèi di sua biltà godere, e del felice letto aver talento: ciascun sembrar nel volto Meraviglia, con fronte crespa e rilevate ciglia. ${ }^{53}\left(\mathrm{I}, 103, \mathrm{Vv} .5^{-8}\right)$

Die Götter werden zu Antlitzen des Staunens. Die « Meraviglia », substanziert zur Idee, bildet den Höhepunkt der Venusdarstellung; sie ist gekoppelt an die Gemachtheit des Reliefs, an den dargestellten Inhalt und implizit auch an die poetische Wiedergabe des Bildes durch den Dichter. ${ }^{54}$

An die Bilder und Reliefs der Venus schliessen Darstellungen von Liebenden an, meist mit einer Metamorphose endend: Es sind « bas-reliefs qui fixent dans l'art et pour l'éternité les exemples des plus miraculeuses histoires d'amour ».55

$5^{1} \quad$ Vera la schiuma e vero il mar diresti, /e vero il nicchio e ver soffiar di venti; [...] (Du nenntest wahr den Schaum und wahr das Meer / Und wahr die Muschel, wahr das Wehn der Winde, / [...], I, 100, Vv. 1-2).

$5^{2}$ Giurar potresti che dell'onde uscissi / la dea premendo colla destra il crino, / coll'altra il dolce pome ricoprissi; / [...] (Du könntest schwören: aus der Woge steigt / Die Göttin, preßt das Haar mit ihrer Rechten, [...], I, 101, Vv. 1-3).

Erfreut von ihrer Schönheit alle Götter / Und voll Verlangen nach dem selgen Lager. / Erstaunen drückt sich aus in jedem Antlitz, / Der krausen Stirn, den hochgezognen Brauen.

54 MAÏER, Ange Politien, S. 347.

55 Ebd., S. 319. 
Wiederum sind die szenischen Darstellungen und Metamorphosen derart echt dargestellt, dass sie das Wahre zu übertreffen scheinen: « Das Wahre selbst ist wahrer nicht als dies » (I, 119, V. 6).

Die Ekphrasis des Palastportals geht nahtlos in die Beschreibung der Venus im Palastgarten über. Venus entsteigt dem Bilderrahmen und wird zur „realen“ Figur, der Amor von seiner neuesten Errungenschaft berichtet - dem « Hauptanführer, ihren Hauptgebieter, / Ihn, der, du weißt, Toskanas Wonne ist» (II, 2, Vv. 3-4).

Venus beschliesst zu Beginn des zweiten Buches, dass Iulio in einem Turnier seine Liebe zu Simonetta unter Beweis stellen solle. Sie entsendet Pasitea mit dem Auftrag, Iulio im Traum zur Turnierteilnahme anzuregen. In diesem Traum wird Iulio von Amor aufgefordert, sich der Gloria zuzuwenden, sodass diese ihn mit den Waffen der Minerva ausstatte und zum Sieg führe. Diese Vision wird getrübt von der Vorahnung von Simonettas Tod. ${ }^{56}$ Trotzdem wacht Iulio erstaunt und mit der Überzeugung auf, in den Kampf zu schreiten. Er ruft Amor, Minerva und Gloria auf, seine Begleiter und Beschützer zu sein.

La rondinella sovra al nido allegra
cantando salutava il nuovo giorno
e già de' Sogni la compagnia negra
e sua spilonca avean fatto ritorno,
quando con mente insieme lieta et egra
si destò Iulio e girò gli occhi intorno:
gli occhi intorno girò stupendo,
d'amore e d'un disio di gloria ardendo. ${ }^{57}$ (II, 39)

Iulios Augen wandern erstaunt umher, erfüllt von Liebe und dem Drang nach Ruhm. Die Zusammenführung der mythologischen mit der historischen Figur Iulios, wie sie im Turnierkampf erfolgt wäre, bleibt in den unvollendeten Stanze aus.

Zusammenfassend lässt sich Folgendes erkennen: Das Staunen begleitet alle Stadien und Ebenen der Erzählung. Von der Bewunderung über die Taten der Medici wird es zum Leitmotiv der mythologisierten Liebesgeschichte sowie der Kunstbetrachtung, bevor es, resultierend aus einem Traum, noch einmal auf Liebe, Ruhm und Ehre gerichtet wird.

56 Puccini, Angelo Poliziano, S. XLV.

57 Auf ihrem Nest die kleine Schwalbe grüßte / Den neuen Tag mit munterem Gezwitscher, / Und heimgekehrt in seine Höhle war / Bereits das schwarze Ingesind der Träume, / Als Julio, frohen und auch schweren Herzens, / Erwachte und die Augen kreisen ließ. / Die Augen ließ er kreisen, ganz erstaunt, / Von Liebe glühend und von Ruhmbegierde. 


\subsection{Die Silvae}

\subsubsection{Einleitende Bemerkungen}

Die vier Silvae Polizianos sind Einführungen in Vorlesungen, die Poliziano in den 148oer-Jahren am Studio Fiorentino in Florenz hielt. Die Einführungen weisen drei elementare Ebenen auf: Erstens wird von der Dichtung im Allgemeinen berichtet (poetologische Ebene), zweitens werden Mythen rund um die Autoren dargelegt (mythologisch-biographische Ebene), drittens werden die Bücher und Werke der Autoren in Form kreativer imitatio nacherzählt (inhaltliche, intertextuelle Ebene). Manto, die als erste Silva 1482 entstand, enthält eine allgemeine Einführung in das Studium der klassischen Texte sowie eine Einleitung in die Bucolica Vergils; die zweite Silva Rusticus (1483) führt in Hesiods Werke und Tage sowie in die Georgica Vergils ein; die dritte Silva Ambra (1485) dient als Auftakt zum Studium der Werke Homers und die vierte Silva Nutricia (1486) berichtet von der antiken Literaturgeschichte im Allgemeinen und von den verschiedenen Genres im Besonderen. ${ }^{58}$ Obwohl als Vorlesungseinführungen präsentiert, handelt es sich bei den vier Silvae nicht um analytische Sachtexte, sondern um literarisch-mythische Darstellungen in lateinischen Hexametern, die in poetischer Form von den Dichtern und deren Texten berichten. Nicht zuletzt sind es die Begeisterung und das Staunen des Redners über diese Texte, die mit den Silvae bezeugt und auf die Zuhörer übertragen werden.

In der Politeia hat Platon jene Dichtung aus dem Staat verbannt, die nicht auf die «ideelle Wirklichkeit» und nicht auf die Vernunft, sondern auf die sinnliche Wirklichkeit und die Leidenschaften gerichtet ist. « Zugelassen bleibt dagegen im Staat ,der Teil von Dichtkunst [...], der Gesänge an die Götter und Loblieder auf treffliche Männer hervorbringt', und zwar weil Dichtung eine für die Erziehung kaum zu unterschätzende Dimension besitzt [... $»^{59}$ Diese von Platon geforderte didaktische Dimension ist zentral für die Silvae. Auch die «musikalische Dimension», verkörpert im Dichtersänger und im Poem, das durchgehend als carmen - «poème chanté » - bezeichnet wird, spielt eine tragende Rolle. ${ }^{60}$ Platon hat die musikalische Komponente der Dichtung stark betont - «weil Zeitmaß und Wohlklang vorzüglich in das Innere der Seele

\footnotetext{
$5^{8}$ BAUSI, Introduzione, S. XI.

59 Steffen Schneider, Kosmos, Seele, Text. Formen der Partizipation und ihre literarische Vermittlung: Marsilio Ficino, Pierre de Ronsard, Giordano Bruno, Heidelberg 2012, S. 39. Vgl. ebenfalls: O. B. HARDison JR., The Enduring Monument. A Study of the Idea of Praise in Renaissance Literary Theory and Practice, Chapel Hill 1962, S. 27.

6o Schneider, Kosmos, Seele, Text, S. 39; Perrine Galand, Introduction, in: Ange Politien, Les Silves, texte traduit et commenté par Perrine Galand, Paris 1987, S. 86-87.
} 
eindringen und sich ihr aufs Kräftigte einprägen [...] ${ }^{61}$ Von Platon wie auch von Poliziano wird die Dichtung in die Nähe des «beschwörenden orphischen Gesang[s] » gerückt, womit ihr eine betörende und verzaubernde Wirkung zugeschrieben wird. ${ }^{62}$

Die Silvae sind insofern eine Erneuerung des literarischen Kommentars, als sie nicht auf eine umfassende inhaltliche Vermittlung oder eine stilistischmetrische Analyse zielen, sondern als innovative poetische Imitation der behandelten Texte angelegt sind. ${ }^{63}$ Die praelectio im klassischen Sinne beinhaltet neben dem Vorlesen eine laus des Autors und des Werkes, gefolgt von einer cohortatio, einem ermunternden Aufruf der Studenten. ${ }^{64}$ Polizianos Silvae behalten diese Bestandteile bei, transformieren das Vorlesen aber in eine eigene, « ambitionierte[] Synthese von Poesie und Philologie ${ }^{65}$ So führt Poliziano in das Leben, die Mythen und die Werke der behandelten Autoren ein, indem er selbst einen «Akt der Poesie» schafft - das heisst nicht nur nach-, sondern neu erzählt. Poliziano negiert damit die Unerreichbarkeit der Antike: Die Möglichkeiten und die Strahlkraft der Poesie erschöpfen sich nicht im Altertum, sondern reichen - über auserwählte Poeten wie Statius, Vergil und Homer - in unsere Zeit hinein und können von zeitgenössischen Autoren weitergeführt werden. Die Titel der Silvae, insbesondere Manto, Ambra und Nutricia - allesamt Musen -, schlagen einen Bogen zwischen lateinischer und griechischer Zeit hin zur Gegenwart. Besonders interessant ist Ambra, deren Mythos von Lorenzo de' Medici in dessen homonymem Gedichtzyklus geschaffen wurde. Lorenzo bezeichnet Ambra als eine Dryade - eine Baumnymphe der griechischen Mythologie -, die vom Flussgott Ombrone verfolgt

Vgl. dazu auch August Buck, Der Orpheus-Mythos in der italienischen Renaissance, Krefeld 1961, S. 17 .

61 Platon, Politeia / Der Staat, Griechisch / Deutsch, bearbeitet von Dietrich Kurz, griechischer Text von Émile Chambry, deutsche Übersetzung von Friedrich Schleiermacher, Darmstadt 1981, 402a. Zitiert aus SchneIDer, Kosmos, Seele, Text, S. 40. Ich ziterie die Politeia sonst unter dem Kürzel Polit. aus der Ausgabe von Platon, Der Staat / Politeia, Griechisch / Deutsch, übersetzt von Rüdiger Rufener, herausgegeben von Thomas Alexander Szlezák, Düsseldorf / Zürich 2000.

62 Perrine Galand-Hallyn, Les yeux de l'éloquence. Poétiques humanistes de l'évidence, Orléans 1995, S. 153. Vgl. ebenfalls Green field, Humanist and Scholastic Poetics, S. 262.

63 Rainer Stillers, Humanistische Deutung. Studien zu Kommentar und Literaturtheorie in der italienischen Renaissance, Düsseldorf 1988, S. 38-39, 62. Es gab kein einheitliches Genre des literarischen Kommentars, gewöhnlich wurden die rhetorischen Formen der prolusio oder der praelectio angewandt. Siehe ebenso Perrine Galand-Hallyn, Maître et victime de la «docte variété ». L'exégèse virgilienne à la fin du Quattrocento, in: Europe 1 (1993), S. 107. Vgl. ebenso GALAND, Introduction, S. 10.

64 GALAND, Introduction, S. 16.

65 BAUsI, Introduzione, S. XII. 
und von Diana - zu ihrem Schutz - in einen Felsen verwandelt wird. Ombrone verfolgt die vor ihm fliehende Nymphe mit unstillbarem Verlangen und steht schliesslich unschlüssig vor dem Felsen: «ma poi, veggendo vana ogni sua voglia, / si ferma pien di maraviglia e doglia. ${ }^{66}$ Schliesslich macht Lorenzo sich selbst zur Figur dieses Mythos. Er tritt in seinem eigenen Poem als Liebhaber Ambras auf, der sich durch sein tugendhaftes Verhalten vom liebeswütigen Ombrone differenziert. Die Keuschheit dieser Liebe ist es denn auch, die das Herz Ambras erobert (40, Vv. 5-8). ${ }^{67}$

Poliziano führt diesen Mythos fort und verändert ihn. Er verweist auf den Mythos Lorenzos, nennt Ambra «mei Laurentis amor», bezeichnet sie aber als Tochter Ombrones, nicht als dessen Geliebte. Er führt die mediceische Geschichte weiter und mythologisiert sie, indem er den Felsen, in den Ambra sich verwandelt, als Ort der Villa Medici in Poggio a Caiano bestimmt. Diese Villa wiederum wird verglichen mit den Mauern Thebens und als unzerstörbares, ewig bestehendes Wunderwerk gepriesen. Die Bedeutung Ambras wandelt sich von der «ninfa caiana » (Ambra, V. 592) in die «villa che durerà fino all'eterno » (V. 598). Nebst den mythologischen Metamorphosen, über die selbst von Figuren innerhalb der Werke gestaunt wird, wird das Werk Lorenzo de' Medicis - sowohl das literarische als auch das politische - als staunensund bewundernswert ausgestellt (Vv. 597-625).

Die Silvae schillern zwischen personaler und institutioneller Dichtung, zwischen authentischer und rhetorischer admiratio.

[...] certains tableaux, certaines descriptions très picturales et colorées, l'harmonie du vers dans certaines images dévoilent [...] une admiration vibrante et sincère de l'Antiquité. On observe un décalage continuel entre l'expression d'émotions authentiquement éprouvées par Politien et celle, purement conventionnelle, d'un enthousiasme fictif. ${ }^{68}$

Les marques d'admiration qui parsèment les Silves ne sont pas non plus purement rhétoriques. Il était nécessaire que le professeur pût exprimer avec clarté ses propres exaltations afin de les faire partager à son auditoire. [...] L'humaniste ne démontre rien, n'impose pas une opinion mais tend à suggérer et à séduire. ${ }^{69}$

66 Lorenzo il Magnifico, Ambra, in:Ders., Poesie, a cura di Federico Sanguineti, Milano 1992, S. 266, 43, Vv. 7-8: «aber dann, alle seine Wünsche als vergebliche erkennend, / bleibt er stehen voller Staunen und Schmerz. » (Übersetzung A. E.)

67 Für den ganzen Abschnitt siehe GaLAND-Hallyn, Les yeux de l'éloquence, S. 203-204.

68 GALAND, Introduction, S. 20-21.

69 Ebd., S. 64. 


\section{Durch diese Haltung unterscheiden sich die Silvae}

[...] von den mit wissenschaftlicher Objektivität erstellten Poetiken späterer Zeit. Für Polizian ist Poesie noch mehr als nur eines der Objekte der Wissenschaft unter vielen anderen, ist Poetik nicht bzw. nicht allein scientia, sondern bedarf ihrerseits des inspirierten vates. ${ }^{70}$

\subsubsection{Das Genre der Silva}

Die Silva ist eine thematisch wie metrisch offene Gedichtform ohne Strophen, die Poliziano in erster Linie von Statius entlehnt, der die Silva als unmittelbares, vielfältiges Gelegenheitsgedicht konzipiert. ${ }^{71}$

Dans leur définition [...] ils [la Miscellanea et les Sylves] sont présentés justement comme des genres sans définition précise, où la fantaisie s'exprime dans la variété plus libre, et bien évidemment étrangers à la hiérarchie des genres et des styles. ${ }^{72}$

Poliziano lobt den epischen Stil und den Themenreichtum der Silva bei Statius:

[...] ita illud meo quasi iure posse videor obtinere eiusmodi esse hos libellos, quibus vel granditate heroica, vel argumentorum multiplicate, vel dicendi vario artificio, vel locorum, fabularum, historiarum consuetudinumque notitia, vel doctrina adeo quadam remota litterisque abstrusioribus nihil ex omni latinorum poetarum copia antetuleris. ${ }^{73}$

70 Dorothea Gall, Polizians Nutricia - Poetik und Literaturgeschichte, in: Ute Ecker und Clemens Zintzen (Hgg.), Saeculum tamquam aureum. Internationales Symposion zur italienischen Renaissance des 14.-16. Jahrhunderts, Mainz 1997, S. 138.

71 Zum Genre derSilva vgl. insbesondere Perrine Galand-Hallyn, Quelques coïncidences (paradoxales?) entre l'Épitre aux pisons d'Horace et la poétique de la Silve (au début du XVI $I^{e}$ siècle en France), in: Bibliothèque d'Humanisme et Renaissance 6o (1998), S. 619; ebenso Virginie Leroux, Le genre de la Silve dans les premières poétiques humanistes (de Fonzio à Minturno), in: Perrine Galand und Sylvie Laigneau-Fontaine, La Silve. Histoire d'une écriture libérée en Europe de l'antiquité au XVIII ${ }^{e}$ siecle, Turnhout 2013, S. $57-78$.

72 JeAn Lecointe, Lidéal et la différence. La perception de la personnalité littéraire à la Renaissance, Genève 2003, S. 318.

73 Angelo Poliziano, Oratio super Fabio Quintiliano et Statii Sylvis, in: Eugenio Garin (Hg.), Prosatori latini del Quattrocento, Milano / Napoli 1952, S. 872. Für die Übersetzung: Angelo Poliziano, Rede des Angelo Poliziano über Fabius Quintilianus und die Silvae des Statius, in: Ders., Vorworte und Vorlesungen, Einleitung, deutsche Übersetzung und Anmerkungen von Otto und Eva Schönberger, Würzburg 2011, S. 96: « Doch meine ich, mit vollem Recht behaupten zu dürfen, dass diese Dichtungen [des Statius] solcher Art sind, dass man ihnen, was epische Größe betrifft, nichts aus der Zahl der ganzen lateinischen Dichter vorziehen darf, ebenso was Vielfalt der Themen angeht, kunstvolle, reiche 
Während Quintilian die Silva aufgrund ihrer spontanen, leichtfüssigen Entstehung als nachlässig gefertigten « Rohstoff» bezeichnet, ${ }^{74}$ bedeutete sie für Statius wie auch für Poliziano einen dichterischen, sowohl inhaltlichen wie auch strukturalen Freiraum, der vielfältig und kreativ - oft in der Form einer Collage - gefüllt werden kann. ${ }^{75}$

Poliziano führt Statius' und Quintilians Äusserungen zusammen, indem er zum einen die offene Form der Silva sowie deren inhaltliche und stilistische Vielfalt, zum anderen aber auch die von Quintilian geforderte Sorgfalt und Gelehrtheit in seine Silvae einbringt. ${ }^{76}$ Sie sind «écriture inspirée» und « extrême érudition » gleichermassen:

Ces quatre poèmes didactiques, fondés sur la docta varietas, se caractérisent à la fois [...] par une écriture inspirée (supportée par une rhétorique de l'exclamation, de la répétition, de l'énumération), et par une extrême érudition (intertexte multiple en latin et en grec, reposant sur des textes souvent rares, allusions mythologiques et historiques complexes, obscurité volontaire du style). ${ }^{77}$

Die Widmung an Lorenzo de' Medici, in der die Silvae als «plump, verbesserungswürdig, [...] unvollendet » angekündigt werden (Manto, Widmung, Vv. 1-4), dürfen wir damit guten Gewissens als Bescheidenheitstopos einordnen.

Das Bild des Waldes - die wörtliche Bedeutung von "Silva“ -, bezeichnet die stilistische und inhaltlicheVielfalt, die Poliziano in den Werken der behandelten Autoren vorfindet, die aber auch für seine eigene Arbeit die leitende Vorgabe darstellt. Dem Dichter stellt sich stets die Aufgabe, grösstmögliche Vielfalt in einer Einheit zu verbinden - gleich einem Wald, der vielfältigste Pflanzen und Lebewesen in einem grossen Ganzen, einem funktionierenden Organismus zusammenhält. ${ }^{78}$ Gleichzeitig ist der Wald ein wachsendes Gebilde und wird dadurch zu einem Sinnbild der Silvae, die Poliziano durch das Zusammenfügen verschiedener Materialien entstehen und gedeihen lässt. ${ }^{79}$

Sprache wie auch Kenntnis der Orte, Sagen, Geschichten, Sitten und Gebräuche sowie erlesene Gelehrsamkeit und Anspielungen auf Entlegenes. »

74 Inst. Orat., X, 3, 17 .

75 GALAND, Introduction, S. 19.

76 Siehe dazu Poliziano, Oratio super Fabio Quintiliano, S. 874.

77 Perrine Galand-Hallyn, Fernand Hallyn und Jean lecointe, Línspiration poétique au Quattrocento et au XVI ${ }^{e}$ siècle, in: Perrine Galand-Hallyn und Fernand Hallyn (Hgg.), Poétiques de la Renaissance. Le modèle italien, le monde francobourguignon et leur héritage en France au XVI siècle, Genève 2001, S. 135.

78 Greene, The Light in Troy, S. 167, 169.

79 Guest, Varietas, S. 47. Zum „Wald“ als Topos sowie den weiteren Topoi der Sylvae siehe ebenfalls S. 34 (ebd.). 
Zu Beginn der Silvae vergleicht sich Poliziano mit einem Vogel im Wald, der sich nicht entscheiden kann, ob er sich auf der Buche, der Eiche oder der Zypresse niederlässt (Manto, Vv. 39-46). Es ist ein Sinnbild für die Fülle an antiken Werken, die es zu studieren gilt, wobei Polizianos Darlegungen dazu dienen werden, dass die Studenten sowohl eine Auswahl einzelner Werke als auch einen Überblick erhalten. Die einzelnen Autoren und Werke, die in den Silvae erwähnt und zitiert werden, sind wichtige Stationen der Literaturgeschichte, ermöglichen aber gleichzeitig in ihrer teilweise anachronistischen und anathematischen Anordnung die Entstehung einer übergeordneten Idee der Dichtung. ${ }^{80}$

\subsubsection{Von Orpheus zu Achill, Homer, Vergil, Poliziano}

Zentraler Topos der Silvae ist der Ursprung der Dichtung, wobei Poliziano sowohl den literaturhistorischen ${ }^{81}$ als auch den mythischen Ursprung beschreibt. Letzterem werden seherische Kräfte und eine wundersame Wirkungskraft zugeschrieben. ${ }^{82}$ Zentral ist die Figur des Orpheus, ${ }^{83}$ bei dessen Gesang nicht nur die Zuhörer erstarren, sondern gleichsam die Gesetze der Natur und der Unterwelt ausser Kraft gesetzt werden. ${ }^{84}$

Finis erat dapibus: citharam excitat Orpheus, et movet ad doctas verba canora manus.

Conticuere viri, tenuere silentia venti, vosque retro cursum mox tenuistis, acquae; iam volucres fessis pendere sub aethera pinnis, iamque truces videas ora tenere feras; decurrunt scopulis auritae ad carmina quercus, nudaque Peliacus culmina motat apex. ${ }^{85}$ (Manto, Vv. 13-20)

8o BAUSI, Introduzione, S. XVIII.

81 In Nutricia.

82 Greenfield, Humanist and Scholastic Poetics, S. 263.

83 Zur Rolle Orpheus' siehe Elizabetr A. Newby, A Portrait of the Artist. The Legends of Orpheus and Their Use in Medieval and Renaissance Aesthetics, New York / London 1987, S. 129, 130, 137; ebenso Warden, Orpheus and Ficino, S. 98; und Gall, Polizians Nutricia, S. 138.

84 Vgl. dazu Inst. Orat., I, 9; ebenso Bettinzo LI, Daedalum iter, S. 82. Es finden sich ähnliche Zeilen in den Eclogae von Pontano, zum Beispiel in der vierten Ekloge Acon, Vv. 6o-65.

85 Ich zitiere aus folgender Ausgabe: Angelo Poliziano, Silvae, a cura di Francesco Bausi, Firenze 1996. Die Auszüge aus den Silvae wurden von der Autorin (A.E.) übersetzt in Anlehnung an bestehende Übersetzungen ins Italienische von Francesco Bausi und ins Französische von Perrine Galand: «Das Festmahl war zu Ende: Orpheus erweckt seine Zither / und bewegt seine gelehrten Hände zu den Worten des Gesangs. / Es verstummten die Menschen, die Winde blieben still, / und ihr, ihr Wasser, kehrtet sobald euren Lauf; / schon sahst du die Vögel mit ihren müden Flügeln in der Luft schweben, / und die wilden 
Orpheos atque lyram curva de valle secutas in caput isse retro liquido pede fluminis undas, cumque suis spelaea feris, cum rupibus ipsis dulcia Pierias properasse ad carmina fagos, quaeque avis applauso libraret in aere pinnas, pene intercepto vix se tenuisse volatu.

Illius argutis etiam patuere querellis Tartara, terrificis illum villosa colubris tergemini stupuere canis latrantia monstra; tum primum et lacrimas, invita per ora cadentes Eumenidum, Stygii coniunx mirata tyranni, indulsit vati Eurydicen; sed muneris usum perdidit: heu durae nimia inclementia legis! ${ }^{86}$ (Nutricia, Vv. 285-297)

Die Flüsse fliessen zurück an ihren Ursprung, Menschen und Tiere stehen still und lauschen erstaunt dem wundersamen Gesang. Doch nicht nur die Wälder beugen sich dem orphischen Gesang, selbst die Bewohner des Tartarus Cerberus und die Gemahlin des Styx - sind ihm untergeben.

In der Praefatio von Manto wird Achilles als Bewunderer und Nachfolger von Orpheus inszeniert, während der Erzähler sich analog als Nachfolger Vergils vorstellt. ${ }^{87}$

Et iam materno permulserat omnia cantu, cum tacuit, querula deposuitque fidem. Occupant hac audax, digitosque affringit Achilles, indoctumque rudi personat ore puer.

Materiam quaeris? Laudabat carmina blandi hospitis, et tantae murmura magna lyrae. Riserunt Minyae; sed enim tibi dicitur, Orpheu, haec pueri pietas grata fuisse nimis.

Tiere sich zurückhalten; / zu diesen Liedern kommen die horchenden Eichen von den Felsen herunter, / und die Spitze des Pelions neigt ihren nackten Gipfel. »

$86[\ldots]$ der Zither von Orpheus in die Krümmungen der Täler folgend / zogen sich die Wogen des Flusses, im fliessenden Lauf, zu ihrer Quelle zurück, / in die Höhlen die wilden Tiere, mit ihren Felsen / eilten die Buchen von Pieria herbei, um den süssen Gesang zu hören, / und die Vögel schwangen ihre Flügel in der Luft zum Applaus, / beinahe ihren Flug unterbrechend und kaum sich haltend. / Zu seinen geistreichen Klagen öffnete sich auch der / Tartarus, und die schrecklichen, bellenden drei Schlangenköpfe / des Kerberos staunten über ihn; / und die Gattin des Herrschers Styx, verwundert über die ersten Tränen / der Erinnyen, die gegen deren Willen von ihren Gesichtern flossen, / gab Eurydike dem Dichter zurück; aber er vergab die Chance des Geschenkes: / Ah, welch übergrosse Strenge des harten Gesetzes!

87 Gall, Polizians Nutricia, S. 129. 
Me quoque nunc magni nomen celebrare Maronis

(si qua fides vero est) gaudet et ipse Maro. ${ }^{88}$ (Manto, Praefatio, Vv. 21-30)

Achilles vollzieht einen Rollenwechsel vom Helden zum Dichter. Der Inhalt sowie der Gestus seines Gesangs sind dem Lob und der Bewunderung des Vorgängers gewidmet, geprägt von den Mitteln der admiratio und der imitatio. ${ }^{89}$

L'admiration (laudabat) et le désir d'imitation sont [...] à l'origine de l'« audace » d'Achille (audax); mais le geste osé de l'enfant, son désir de suivre les traces du divin poète proviennent d'un sentiment de ferveur, pietas [dévotion], et ce terme désigne l'enthousiasme sacré des jeunes humanistes. L'admiration de l'élève pour le maître ne demeure pas unilatérale, un échange affective a lieu; à la pietas d'Achille répondent la reconnaissance et le plaisir d'Orphée: grata; en outre, la restriction rhétorique dicitur, ainsi que l'adverbe nimis, dont le sens est très appuyé, suggèrent peut-être même que l'amusement ému d'Orphée a pu se transformer en un sentiment plus profond..$^{90}$

Der Erzähler ergänzt seine Rolle als Nachfolger Vergils, wenn er sich wenige Zeilen weiter als Nachfolger Orpheus' präsentiert, ${ }^{91}$ wobei er mit seiner Figur nicht nur jene des Achilles überlagert, sondern zudem Herkules ins Spiel bringt (Manto, Vv. 33-40). Wie Orpheus will der Erzähler die Sirenen zum Verstummen bringen, und zwar mit einem kühnen Gesang («audaci [...] canti»), als wolle er - wie Herkules - die Säulen von Atlantis stützen. ${ }^{92}$

Herkules wiederum wird in Ambra mit Homer verglichen, da dessen Dichtung dieselben Kräfte wie Herkules' «ferrum lapis» zugeschrieben werden. Die übernatürliche Kraft des Steins von Herkules wird in Analogie zum geheimnisvollen Furor («arcano [...] furores», Ambra, V. 13) gesetzt,

88 Und schon hatte er mit dem mütterlichen Gesang alles beruhigt, / als er schwieg und die wimmernde Lira ablegte. / Mutig nimmt Achilles sie an sich, lässt seine Finger darüber gleiten, / und der Junge lässt einen rohen, ungebildeten Gesang erklingen. / Wovon er handelt, fragst du? Er lobte die Dichtungen des reizenden Gastes, / das bedeutungsvolle Rauschen seiner mächtigen Laute. / Es lachten die Minyer; aber es wird von dir erzählt, Orpheus, / dass dir die Ehrfurcht des Jungen nur allzu angenehm war. / Nun, auch ich werde den Namen des grossen Vergil zelebrieren, / sodass Vergil selber (wenn mein Glaube wahr ist) sich darüber freut.

89 Die Kühnheit des Dichters wird unter anderem auch bei Quintilian erwähnt: Inst. Orat., VIII, 11. Zur imitatio siehe GALAND, Introduction, S. 107.

9o GALAND, Introduction, S. 31-32.

91 Mit dem volkssprachlichen Drama Fabula di Orfeo (1480) hat sich Poliziano wenige Jahre vor den Sylvae als origineller Erzähler der Liebesgeschichte von Orpheus und Eurydike hervorgetan.

92 Ficino hat Poliziano „Herkules“ genannt, « for his skill at slaying the monsters of textual corruption ». Siehe WARDEn, Orpheus and Ficino, S. 87. 
der aus Homers Dichtung strömt. ${ }^{93}$ Während Herkules kraft seiner Stärke Wunder vollbringt, schafft Homer poetische Wunder: Homer überträgt uns Menschen den Kelch des Ganimedes, der Unsterblichkeit verheisst. ${ }^{94}$ Mit seiner Dichtung hebt er die Menschen in die himmlisch-göttliche Sphäre, mit seinem beflügelten Geist zeigt er uns das Angesicht der Götter, die Unterwelt, den Himmel, die Erdteile und die Meere, er enthüllt uns Lesern die Essenz der Dinge, er führt die Stimmen der Tiere, der Vögel, des Windes, des Feuers, der Meere und Flüsse, der Menschen und der Götter vor (Ambra, Vv. 19-26). Am Ende von Ambra wird Homers gesamtes Werk als «vortreffliche Dichtung » bezeichnet, die die Natur in Verwunderung und Staunen versetzt (Ambra, V. 574). An dieser Stelle tritt eine Überlagerung der Figur Homers nicht nur mit dem Helden Achilles und dem Sänger Orpheus ein, sondern auch eine Gleichsetzung mit Jupiter, wenn Homer als Weltenregler erscheint:

[...] dum nigris mota laborant
cuncta superciliis, immortalesque secuntur
astra iubas, sancta dum maiestate tremendum
excipiunt magnoque assurgunt numina patri;
heroumque idem facies, et celsa potentum
ora deum, variisque horrenda animalia formis,
diversasque urbes positusque habitusque locorum
innumeros, sensusque animorum, carmine pulchro,
naturamque omnem, illa ipsa mirante, figurat.95 (Ambra, Vv. ${ }^{566-574)}$

In der neuplatonischen Philosophie gilt Jupiter als mythologisches Symbol der Einheit des Kosmos. ${ }^{96}$ Aus Zeus geht die Welt hervor und zu Zeus kehrt alles wieder zurück. Indem der Dichter mit Zeus gleichgesetzt wird, werden ihm diese schöpferischen Qualitäten zuerkannt: Der Dichter kreiert mit seinem Gesang die Welt und führt diese wie auch die Zuhörer durch den Gesang

93 Francesco Bausi, Commento, in: Poliziano, Silvae, S. 103.

94 Dass Homer im Reich der Götter angesiedelt wird, ihnen ebenbürtig und mit ebensolchen wundersamen Fähigkeiten ausgestattet, lesen wir auch in den Versen 457-466 von Ambra.

$95[\ldots]$ während alles sich bewegt / beim Wink seiner schwarzen Augenbrauen und die Sterne / seiner unsterblichen Haarpracht folgen, während die Götter ihn empfangen, zitternd / vor seiner heiligen Grösse und sich erheben vor dem erhabenen Schöpfer; / und die Antlitze der Helden und die hervorragenden Gesichter der mächtigen / Götter und die verschiedenartigen Gestalten furchterregender Tiere / und die vielfältigen Städte und die Lage und die unzähligen Bräuche der Orte / und die Empfindungen der Lebewesen und die gesamte Natur / er in seiner wunderbaren Dichtung darstellt (sodass diese selbst erstaunt ist). // Vgl. dazu auch die Verse 457-466 aus Ambra; an dieser Stelle wird Homer explizit mit Jupiter gleichgesetzt.

96 Warden, Orpheus and Ficino, S. 92-93. 
wieder zur Einheit des Universums zurück. Umgekehrt wird auch Jupiter als Musiker und Sänger dargestellt; seine Schöpfungskraft ist poetischer Natur. Er dirigiert die himmlische Harmonie, die den Weltenlauf bestimmt und von den Dichtern erahnt und nachgeahmt wird. ${ }^{97}$ Der Göttervater Jupiter formt mit seiner « cithara » Intervalle, die für uns unregelmässig und unergründlich scheinen, denen jedoch himmlische Gesetze der Proportion zugrunde liegen (Nutricia, Vv. 146-151).

Jeder himmlisch-klanglichen Sphäre steht eine Muse vor, die die Götter mit ihrem unsterblichen Gesang betört. Ein Abbild («simulachra », V. 156) dieser Sphären wiederum leuchtet in auserwählten Menschen (Dichtern) auf, entzündet, läutert und ermächtigt sich deren Seelen (Vv. 158-162), sodass sie in einen Zustand der Entrückung geraten.

[...] Mirantur et ipsi

saepe (quis hoc credat?) quae nuper cumque, recepto

numine, legitimi cecinere oracula vates;

$[\cdots]$

[...] quin sancta legentem

concutiunt parili turbam contagia motu,

deque aliis alios idem proseminat ardor

pectoris instinctu vates; ceu ferreus olim

anulus, arcana quem vi Magnesia cautes

sustulerit, longam nexu pendente catenam

implicat et caecis inter se conserit hamis. ${ }^{98}$ (Nutricia, Vv. 182-196)

Über das Ergebnis der Ekstase - einen Gesang, der alles überragt und nicht einmal vom Donner des Jupiter übertönt werden kann (Nutricia,

97 Die Idee des Erfülltseins vom « concentus mirabilis » der himmlischen Sphären sowie dessen Auswirkung auf die kreative Schöpfungskraft gehen auf Ficino zurück: «Das Erfülltwerden von der Schönheit der musica caelestis regt die Seele zugleich zu aktiver imitatio dessen an, was sie in sich aufgenommen hat. » Siehe Alfons Reckermann, Das Konzept kreativer imitatio im Kontext der Renaissance-Kunsttheorie, in: WALter HaUg und Burghart Wachinge R (Hgg.), Innovation und Originalität, Tübingen 1993, S. 129 .

98 [...] Selbst die echten Seher / (wer hätte das gedacht) erstaunen oft und immer wieder vor den Orakeln, / die sie, erfüllt vom göttlichen Wesen, verkündet haben. /[...] wie eine heilige Ansteckung / erschüttern sie die lesende Schar mit der gleichen Erregung, / und das Glühen, die göttliche Eingebung des Herzens, / setzt sich von den Dichtern fort; gleich wie einst ein eiserner Ring, / der von der geheimnisvollen Kraft eines magnetischen Steins / hochgehoben wurde, verwickelt zu einer langen Kette, / die Haken blind aneinanderreihend. 
Vv. 178-182) - staunen die Dichter.99 Es bleibt ihnen zu beobachten, wie die poetische Glut («ardor ») sich auf die Leser überträgt.

[...] le disciple est saisi d'admiration devant les mystères que son maître lui enseigne, et le maître lui-même ne peut que constater avec émerveillement, une fois encore, le miracle renouvelé de la „contagion poétique“ (191-193). ${ }^{100}$

Im Ion hat Platon die Übertragung der poetischen Energie als Bewegung von den Göttern und Musen auf den Dichter, von diesem auf den (passiven) Rhapsoden und über dessen Vortrag auf die Zuhörer konzipiert. Ficino entwickelt diese Übertragungsbewegung weiter, indem er die inspirierten Zuhörer zu neuen Schöpfern poetischer Texte werden lässt.

Memento vero cantum esse imitatorem omnium potentissimum. [...] tamque vehementer omnia imitatur, \& agit, ut ad eadem imitanda, vel agenda, tum cantantem, tum audientes subito provocet. ${ }^{101}$

Poliziano umschreibt dieses Phänomen so, wie er es selbst bei Ficinos Rezitation orphischer Hymnen erlebte:

Oft verjagt er mit seiner gelehrten Laute die schweren Sorgen

Und nimmt seine Stimme hinzu mit tönenden Worten

Wie es von Orpheus, dem Meister des apollinischen Gesangs

Heißt, er habe die wilden Tiere Odrysiens gezähmt.

$[\ldots]$

Darauf, wo er schweigt, werde ich, von musischer Begeisterung ergriffen, geradewegs hinabgeführt zu den vertrauten Laren

99 Donatella Coppini, L'ispirazione per contagio: «furor $» e$ «remota lectio » nella poesia latina del Poliziano, in:Vincenzo Fera und Mario Martelli (Hgg.), Agnolo Poliziano. Poeta scrittore filologo, Atti del Convegno Internazionale di Studi, Montepulciano 3-6 novembre 1994, Firenze 1998, S. 127. Vgl. ebenso Cristoforo LAndino, Disputationes Camaldulenses, herausgegeben von Peter Lohe, Firenze 1980, S. 112-113; und Cristoforo Landino, Praefatio in Virgilio, in: Roberto Cardini, La critica del Landino, Firenze 1973, S. 21. Gesehen bei HÉLÈne CASANova-Robin, Étude introductive, in: Giovanni Pontano, Églogues / Eclogae, étude introductive, traduction et notes par Hélène Casanova-Robin, Paris 2011, S. CCXLII.

100 GALAND, Introduction, S. 40.

101 Marsilio Ficino, De Vita libri tres, Book VIII: De Vita Coelestis Comparanda, in: De rs., Opera Omnia, 2 Bde., Basel 1576, S. 563: «Erinnere dich, dass der Gesang wahrhaftig der mächtigste Nachahmer von allem ist [...] [er] bildet und gestaltet alles derart energisch nach, dass er den Sänger und die Zuhörer unmittelbar anregt, dasselbe auf eine ähnliche Art und Weise nachzuahmen und hervorzubringen. » (Übersetzung A.E.) Zitiert aus Newby, A Portrait of the Artist, S. 154, Fn. 29. 
und ersinne meinerseits Verse und fordere Phoebus heraus und verzückt schlage ich die heilige Leier mit dem Plektrum. ${ }^{102}$

Eine Reihe namhafter Persönlichkeiten, darunter Lorenzo und Cosimo de' Medici, wohnte diesen Sessionen bei und berichtete von der erstaunlichen Wirkung, die die orphischen Gesänge Ficinos auf sie ausübten: «Orphei hymnos exposuit, miraque ut ferunt dulcedine ad lyram antiquo more cecinit. »103

Poliziano entwickelt Ficinos Konzeption des Furors fort, indem er zum einen die Dichtung emanzipiert, das heisst sie nicht primär in den Dienst der (Gottes-)Erkenntnis, der Anamnesis und des Aufstiegs zum Göttlichen stellt. ${ }^{104}$ Zum anderen - und das ist für unsere Thematik entscheidend - koppelt er die Übertragung des Furors an die admiratio. Die Funktionsweise der admiratio ist jene der contagio - ein Begriff aus der Sphäre des Menschlichen, nicht des Göttlichen -, mit der die « astral causation » des Furors zurückgewiesen und an dessen Stelle eine « human agency» gesetzt wird. ${ }^{105}$

Für Ficino ist der poetische Gesang ein Abbild der wunderbaren Ordnung, der zyklischen Bewegungen und der Harmonie der Welt und des Kosmos. Wenn der Gesang Verwunderung auslöste, dann vor der Grösse dieser Ordnung. ${ }^{106}$ Bei Poliziano hingegen ist die admiratio in erster Linie auf die Texte und deren Schöpfer gerichtet - nicht die Wunder des Himmels, sondern die der Dichtung stehen im Mittelpunkt. ${ }^{107}$ Der poetische Text bildet nicht die Schöpfung nach, sondern ist selbst Schöpfung (Nutricia, Vv. 566-574). ${ }^{108}$

Es zeigt sich, dass der mythische Ursprung der Dichtung - die staunenerregende Wirkung der Dichtung des Orpheus - wie auch der Inspirationsprozess -

102 «Die Verse stammen aus einem Gedicht an Bartolomeo Fonzio [...]» Ich zitiere die deutsche Übersetzung von Schneider, Kosmos, Seele, Text, S. 32. Schneider entnimmt das Zitat aus: PAUl O. KRisteller, Supplementum Ficinianum, Florenz 1937, S. 282-283.

103 Warden, Orpheus and Ficino, S. 87. Warden zitiert aus C. G. Corsi, Vita Marsilii ficini 6, printed as Appendix I in: Raymond Marcel, Marisile Ficin, Paris 1958: «Er führte die Orphischen Hymnen auf und sang sie, wie man sagt, mit wundervoller Süße auf die Art der Antike. » Die Übersetzung stammt aus: Volkhard Wels, Der Begriff der Dichtung in der Frühen Neuzeit, Berlin 2009 (= Historia Hermeneutica, Series Studia, Bd. 8), S. 212.

104 Für Ficino ist Dichtung Mittel zum Zweck, um zu Transzendenz und Einheit mit Gott zu gelangen. Kunst und Kreativität sind keine autonomen Akte. Siehe Newby, A Portrait of the Artist, S. 42.

105 Guest, Varietas, S. 28.

106 André Chastel, Marsile Ficin et l'art, Genève / Lille 1954, S. 57.

107 WaRden, Orpheus and Ficino, S. 89.

108 An dieser Stelle wird Homer die Rolle Jupiters, des Weltenreglers, zugeschrieben. 
die Übertragung und die Erzeugnisse des furor poeticus - an das Staunen gekoppelt und über dieses definiert werden.

\subsubsection{Der Dichter als erstaunlicher Mythos \\ 1.4.4.1 Vergil ${ }^{109}$}

[...] l'originalité de Politien éclate particulièrement dans cette introduction qui n’annonce que très brêvement le sujet [...], mais qui plonge immédiatement les auditeurs dans le monde de la poésie et du merveilleux..110

Wie Perrine Galand dies richtig ausdrückt, bietet Manto - die Einführung in Vergils Bucolica - keine Einleitung im eigentlichen Sinne, sondern setzt unmittelbar im mythologischen Kontext ein. Nach einer Praefatio, die von Orpheus' wunderbarem Gesang und Achilles als seinem Nachfolger berichtet, schwenkt die Silva zur Göttin Nemesis, die Griechenland für seinen Hochmut bestraft und vom Thron der Rhetorik und Poetik stösst. Wie ein Kriegsgefangener wird Griechenland unter das Joch der lateinischen Redner und Dichter gestellt und die Geburt Vergils - jenes Dichters, der Hesiod und Homer übertreffen wird wird prophezeit:

Editus ecce Maro, quo non felicior alter, seu silvas seu rura canit sive « arma virumque »: namque Syracosiis cum vix assurgat avenis, Hesiodum premit et magno contendit Homero. ${ }^{111}$ (Manto, Vv. 29-32)

Die Geburt Vergils wird von einer mythischen Aura umgeben, hinter der die biographischen Fakten verschwinden:

Te nascente, Maro, Parnassi e culmine summo affuit Aonias inter festina sorores

Calliope, blandisque exceptum sustulit ulnis, permulsitque manu quatiens, terque oscula iunxit, omina ter cecinit, ter lauro tempora cinxit. ${ }^{112}$ (Vv. 47-51)

109 Die Verszitate in diesem Kapitel beziehen sich, wenn nicht anders vermerkt, auf Manto.

110 GALAND, Introduction, S. 56 .

111 Seht, Vergil wird geboren, gesegnet wie kein anderer, / ob er die Wälder, den Landbau oder die Waffen und den Helden besingt: / und auch wenn er die Hirtenpfeifen aus Syrakus nur mit Mühe übersteigt, / steht er über Hesiod und setzt sich gegen den grossen Homer durch.

112 Als du geboren wurdest, Vergil, kam vom höchsten Gipfel des Parnass, / von den aonischen Schwestern eilend / Kalliope herbei: sie nahm dich empor und hielt dich in den sanften Armen, / sie wiegte dich, berührte dich sanft mit der Hand und verband sich 
Kalliope eilt von den Gipfeln des Parnass herbei, um Vergil zu wiegen und ihn rituell in die Sphäre der Dichtung einzuweihen.

Nascetur, video, supera tibi missus ab arce sidereus vates, alti cui numinis haustum mens caelo cognata ferat, quem grande sonantem non Linus Inachides tantum atque Oeagrius Orpheus aut mea qui Tyrio construxit moenia plectro, sed vos, o Musae, sed mireris, Apollo. ${ }^{13}$ (Vv. 69-74)

Vergil kommt als gestirnter Dichter bzw. Seher («sidereus vates») $)^{114}$ zur Welt; er ist dem Himmel verwandt («mens caelo cognata ferat») und stellt so eine Mittler- und Mittelposition zwischen Menschlichem und Göttlichem dar. ${ }^{115}$ Er wird nicht nur in einer Reihe mit den grossen Sängern der Mythologie (Linos, Orpheus) genannt, sondern diese werden anachronistisch als Bewunderer Vergils vorgestellt. Sogar Amphion, bei dessen Saitenspiel sich die Mauersteine von Theben von allein zusammengefügt haben, wie auch Apollon und seine Musen erstaunen über den Gesang Vergils. Die Verse 71-74 laufen grammatikalisch auf «sed mireris » zu: Das Staunen über den Gesang Vergils verbindet und umfasst als Klimax die Sänger, die Musen und Apollon.

Der Sternenhimmel hat eine weitere zentrale Bedeutung, insofern als er den Raum des Erinnerns bildet. Die Dichter gehen aus den Gestirnen hervor, um mit ihren Gesängen Erinnerungsräume und -orte (Himmel und Sterne) zu schaffen, in die sich die fama der Dichter sowie der von ihnen beschriebenen Helden, Fürsten und Figuren einschreibt. Diese Räume funktionieren analog dem dichterischen Text als eine kosmologisch-mythologische Topographie, die dem Lob und der Erinnerung dient. ${ }^{116}$ Die Erinnerung wiederum sowie der

mit drei Küssen mit dir, / dreimal besang sie dich, dreimal schmückte sie deine Schläfen mit Lorbeer. // Die rituelle Einweihung Vergils findet sich auch in den Versen 56-57.

113 Es wird geboren - ich sehe es -, zu dir geschickt von den hohen Sphären /, ein gestirnter Dichter, dessen dem Himmel verwandter Geist / durchdrungen ist von der hohen Gottheit; sein grossartiger Gesang / wird nicht nur von Linos dem Inachiden und Orpheus dem Thraker bewundert werden / oder von Amphion, der mit seiner Laute meine Mauern errichtet hat, / sondern auch ihr, oh Musen und du, oh Apollon, werdet ihn bestaunen. // Es handelt sich um das von der Muse ausgesprochene Orakel; durch die Muse wiederum spricht Apollon. Siehe Manto, Vv. 259-26o.

114 An dieser Stelle wäre ein Vergleich mit dem Orphischen Hymnus an den Sternenhimmel sehr spannend. Einen ersten Eindruck gibt SCHNeIdE R, Kosmos, Seele, Text, S. 29-31.

115 Zu Vergil als poeta theologus siehe BAusi, Commento, S. 14-15.

116 So auch bei Ficino, der die unzerstörbare Erinnerungskraft als eine der wesentlichen Gaben des Kunstwerkes beschreibt. Siehe Chastel, Marsile Ficin et l'art, S. 61. 
Ruhm sind an das Staunen gekoppelt: Nur staunenerregende Dichtung bleibt in das Gedächtnis eingeschrieben (vgl. V. 308 und siehe unten).

Die Geburt Vergils wird von Manto prophezeit und Manto wird seine ispiratrice sein (V. 313). Die Figur Mantos steht paradigmatisch für Polizianos Eklektizismus, das Ineinander- und Übereinanderlegen verschiedener kultureller und literarischer Bezüge. In der griechischen Mythologie ${ }^{117}$ ist Manto die Tochter von Teiresias und besitzt - wie ihr Vater - die Gabe der Prophetie. Sie gilt als Gründerin des apollinischen Orakels bei Kolophon. In Ovids und Vergils Werk vermählt sich Manto mit dem Flussgott Tiberinus; der gemeinsame Sohn Ognus gilt als Gründer von Mantua - der Geburtsstadt Vergils. ${ }^{118}$ Statius beschreibt in seiner Thebais, wie Manto nach dem Tod ihres Vaters während der Belagerung Thebens durch viele Länder gezogen ist, bevor sie sich an den Ufern des Mincio niedergelassen hat, wo aus den Tränen, die sie für ihren Vater vergossen hat, ein See entstand. Manto verbindet als Figur das antike Griechenland mit Italien sowie die Sprache und Dichtung beider Länder. Diese Verbindung spiegelt sich auch in Vergil wider, wenn er als «Aonius iuvenis » beschrieben, seine Herkunft an die Bewohner Böotiens - insbesondere die Musen -, an die Gegend um Theben sowie an den Tempel Apolls gebunden wird. ${ }^{119}$

Die Prophezeiung Mantos richtet sich an die « magnanimi heroes » und verspricht ihnen Ruhm und Erinnerung durch den kommenden Dichter:

Grande tamen vobis leti solamen honesti, magnanimi heroes nati felicibus astris, afferet Aonius iuvenis, cui dia canenti facta virum totis pariter praeconia linguis solvet Fama loquax, cui dulci semper ab ore roscida mella fluent, cuiusque Acheloia Siren gestiet innocuo divina poemata cantu flectere, cui blandis insidet Suada labellis, cui decus omne suum cedet stupefacta vetustas. ${ }^{120}$ (Vv. 30o-3o8)

117 Siehe das Lemma «Manto » in Der kleine Pauly. Lexikon der Antike, Bd. 3, Stuttgart 1969, S. 980.

118 Vergil, Aeneis, Lateinisch / Deutsch, übersetzt und herausgegeben von Edith und Gerhard Binder, Stuttgart 2008, 10, 198. Verweise und Zitate aus der Aeneis werden in der Folge mit Aen. wiedergegeben.

119 Vgl. auch Ambra, 286; ebenso BAUsi, Commento, S. 36.

120 Aber grossen Trost für euren ehrenvollen Tod, / oh ihr grossen Helden, die ihr unter begünstigten Sternen geboren wurdet, / wird der böotische Jüngling überbringen: Ihm, der die göttlichen Handlungen / der Helden besingen wird, wird die redselige Fama mit allen ihren Zungen / ebensolche Verherrlichung zukommen lassen; aus ihrem süssen Mund / wird immer tauender Honig fliessen; die Sirene Acheloia begehrt danach, / 
Vergils Aufgabe wird es sein, die Taten der Heroen zu verherrlichen, und zwar mit einem lieblichen Gesang, der wie Orpheus den mächtigen Gesang der Sirenen wirkungslos macht. Die Dichtung Vergils ist derart graziös - die Grazie Suada wird sich auf seine Lippen legen -, dass ihm das erstaunte und verblüffte Altertum («stupefacta vetustas ») Ruhm und Ehre zollt. Ruhm und Ehre sowie die Erinnerung sind somit Folgen des Erstaunens, in das der dichterische Gesang das Publikum zu versetzen vermag.

Von grosser Bedeutung ist der Übergang von der Fama, die Vergil mit allen ihren Zungen beim Preisen der grossen Heldentaten beiseitesteht, zum Ruhm, der nicht mehr dem Helden, sondern dem Poeten gezollt wird. Am Ende bleibt nur die Dichtung - alles andere, selbst die Helden, sind vergänglich. Das zeigt sich auch im Vergleich der Dichtung mit den sieben Weltwundern (Vv. 325350), deren Vergänglichkeit - der Erosion der Zeit und dem Wüten der Götter ausgeliefert - der Unsterblichkeit literarischer Werke gegenübergestellt wird. Solange das Meer ein- und ausfliesst, solange sich die Elemente vermischen und immer wieder neue Formen hervorbringen, werden Vergils Werke unsterblich sein. ${ }^{121}$ Die Verbindung von Zyklizität und immerwährendem Lob für den Dichter wird anhand von Anaphern vorgestellt:

at manet aeternum et seros excurrit in annos vatis opus: $[\ldots]$

[...] semper erit magni decus immortale Maronis, semper inexhaustis ibunt haec flumina venis, semper ab his docti ducentur fontibus haustus, semper odoratos fundent haec gramina flores, unde piae libetis apes, unde inclyta nectat serta comis triplici iuvenilis Gratia dextra. Et quis, io iuvenes, tanti miracula lustrans eloquii, non se immensos terraeque marisque prospectare putet tractus? [... $]^{122}$ (Vv. $\left.33^{8}-353\right)$

dessen göttliche Dichtungen mit harmolosem Gesang zu verkünden; / auf seine zärtlichen Lippen wird Suada sich legen / und ihm wird das erstaunte Altertum jeglichen Ruhm eingestehen.

121 Die zyklische Auffassung der Zeit wurde insbesondere von Ficino propagiert, der darin eine Manifestation sowie eine Analogie zu den ewigen, proportional-harmonischen Bewegungen der himmlischen Sphären sah.

122 Aber das Werk des Poeten bleibt in Ewigkeit / und geht über lange Jahre hinaus: [...] / [...] der unsterbliche Glanz des grossen Maro wird ewig währen, / immer werden diese Flüsse aus unerschöpflichen Adern fliessen, / immer wird aus seinen Quellen Gelehrtes geschöpft werden, / immer werden aus diesem Boden wohlriechende Blüten hervorgehen, / von diesen, treue Bienen, möget ihr trinken, von diesen möge / die jugendliche Grazie gewandt die berühmten Girlanden in ihr Haar flechten. / Und wer, oh 
In diesem Abschnitt zeigt sich der dynamische Charakter der Dichtung. Diese wird nicht museal verehrt, sondern aus ihrem Nektar gehen immer wieder neue Lehren hervor, entstehen immer wieder neue wohlriechende Blüten, an denen die jungen Dichter sich nähren können. Aus den den leuchtenden Wundern der Redekunst («miracula lustrans / eloquii ») schöpft sich die ganze Welt, lassen sich die Weiten der Erde sowie der Meere ermessen.

Poliziano schafft das Bild eines Flusses, der in seiner Vielgestaltigkeit die Vielfalt der Dichtung darstellt.
Sic varios sese in vultus facundia dives induit: et vasto nunc torrens impete fertur fluminis in morem, sicco nunc aret in alveo; nunc sese laxat, nun exspatiata coercet; nunc inculta decet, nunc blandis plena renidet floribus; interdum pulchre simul omnia miscet. ${ }^{123}$ (Vv. $362-367$ )

Ihren Höhepunkt erreicht die Dichtung dann, wenn sich verschiedene Stile in ihr vereinen, wenn ihre discordia concors auf die harmonische Vielfältigkeit der Natur verweist. ${ }^{124}$

In der variatio verbinden sich wie in der admiratio sowohl produktions- als auch wirkungsästhetische Aspekte. Für das literarische Schaffen geht es nicht nur darum, Verschiedenes zusammenzubringen, sondern auch darum, das Verschiedene auf kunstvolle und überraschende Weise zu verbinden. Dadurch ist die variatio nicht nur Bestandteil der delectatio und Mittel gegen die Monotonie, ${ }^{125}$ sondern insbesondere dazu bestimmt, Staunen zu erzeugen. In der variatio kann Ungewöhnliches miteinander vereint werden. ${ }^{126}$ Nicht nur für Pseudo-Longin ist das paradoxon eines der zentralen Mittel, um admiratio hervorzurufen, auch für Poliziano sind das Ungewöhnliche und das Kontroverse bevorzugte Mittel, um Staunen bei den Lesern auszulösen. ${ }^{127}$

ihr Jünglinge, so viele Wunder der Redekunst umkreisend, / hat nicht das Gefühl, die immense Ausdehnung von Land und Meer / zu erahnen? // Zur Metapher der Biene vgl. u. a. Green field, Humanist and Scholastic Poetics, S. 268.

123 Gleichsam kleidet sich die reiche Redegabe mit mannigfachen Zügen: / So ist sie einmal ein Sturzbach, hervorgebracht / von einem stürmischen Drang wie der eines vollen Flusses, / einmal ruht sie trocken in einem Flussbett; / einmal entspannt sie sich, einmal bändigt sie sich, nachdem sie abgeschweift war; / einmal geht sie unkultiviert vor, einmal erstrahlt sie in voller Blüte / und manchmal bringt sie alles wunderbar zusammen.

124 Galand-Hallyn, Les yeux de l'éloquence, S. 220-221.

125 Siehe das Lemma « Variation » in Historisches Wörterbuch der Rhetorik, Bd. 9, S. 1006-1015.

126 GALAND, Introduction, S. 108.

127 Betrinzoli, Daedalum iter, S. 110. Für Pseudo-Longin und die Bedeutung des paradoxon für die admiratio (thaumaston) siehe das Lemma «Admiratio » in Historisches 


\subsubsection{Homer ${ }^{128}$}

Igitur, ut Aratus ab Iove incipiendum putat, ita nos rite coepturi ab Homero videmur. hic enim, quem ad modum ex Oceano dicit ipse amnium fontiumque cursus initium capere, omnibus eloquentiae partibus exemplum et ortum dedit. hunc nemo in magnis rebus sublimitate, in parvis proprietate superaverit. idem laetus ac pressus, iucundus et gravis, tum copia tum brevitate mirabilis, nec poetica modo, sed oratoria virtute eminentissimus. ${ }^{129}$

Nicht umsonst führt Poliziano diese Stelle Quintilians in seiner Vorlesung zu Homer an. Neben Vergil ist Homer sein grosses literarisches Vorbild: Homers Sprache wird gleichsam als Ursprungssprache verehrt; alle Bereiche der Beredsamkeit haben in ihr ihren Ausgang genommen.

Utque parens rerum fontes et flumina magnae

suggerit Oceanus terrae, sic omnis ab istis

docta per ora virum decurrit gratia ${ }^{130}$ chartis;

hinc fusa innumeris felix opulentia saeclis

ditavit mentes, tacitoque infloruit aevo. ${ }^{131}$ (Ambra, Vv. 476-480)

Wie um Vergil wird auch um Homer ein reich ausgeschmückter Mythos geschaffen. ${ }^{132}$ Besonderes Augenmerk wird diesmal auf die Vorgeschichte der Geburt gelegt. Thetis beklagt sich bei Jupiter, dass ihr Sohn Achilles dem

Wörterbuch der Rhetorik, Bd. 1, S. 108. Siehe ebenso Lecointe, L'idéal et la différence, S. 317: «[...] le concept de variété tend à renvoyer de plus en plus, chez Politien, [...] à l'inattendu, l'insolentia, la nouveauté, l'irrégularité.»

128 Die Verszitate in diesem Kapitel beziehen sich, wenn nicht anders vermerkt, auf Ambra.

129 Inst. Orat., X, 1, 46: «Da nun scheint es uns recht und fromm, so wie Arat glaubt, mit Juppiter habe sein Lied zu beginnen, wenn wir mit Homer den Anfang machen. Hat er doch so, wie nach seinen eigenen Worten im Ozean Ströme und Quellen immer wieder ihren Lauf beginnen, allen Bereichen der Beredsamkeit Vorbild und Ursprung geliefert. Niemand könnte ihn bei großen Geschehnissen an Erhabenheit, bei kleinen an treffender Genauigkeit überbieten. Üppig zugleich und schlicht, lieblich und ernst, bald in seiner Fülle, dann wieder in seiner Kürze staunenswert ist er nicht nur an dichterischer, sondern auch an rednerischer Meisterschaft der hervorragendste. » Poliziano zitiert diese Stelle in Angelo Poliziano, Rede des Angelo Poliziano bei seiner Erklärung des Homer, in: DE RS., Vorworte und Vorlesungen, S. 84.

130 Bausi übersetzt «gratia» mit « ornamento », viel eher als der Redeschmuck scheint mir an dieser Stelle jedoch die Anmut der Sprache Homers gemeint.

131 Und wie der Ozean, Vater aller Elemente, Quellen und Flüsse / der grossen Erde unterstützt, so entspringt dieser Schrift / jede weise Anmut in der Sprache der Menschen; / von hier bereicherte ein gesegneter Reichtum den Geist / unzähliger Jahrhunderte und erblühte im stillen Lauf der Zeit.

132 Galand-Hallyn, Les yeux de l'éloquence, S. 193. 
Vergessen anheimgegeben, seinen heroischen Taten keine Unsterblichkeit durch fortwährende Loblieder geschenkt würde. Jupiter verspricht ihr, dass Fama unermüdlich mit hundert Mündern Lobgesänge auf Achilles singen werde (V. 155) - gemeinsam mit Homer, dessen Geburt er prophezeit:

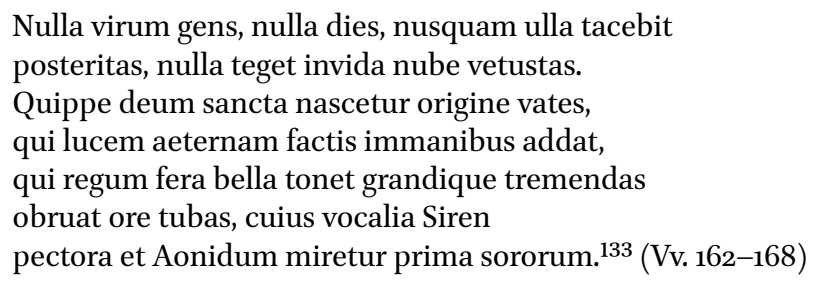

Ein Dichter göttlicher Abstammung wird geboren werden, der die Taten Achills in Ewigkeit erleuchten, der die Kriege nicht nur erklingen lässt, sondern sie mit seiner Stimme übertönt, sodass die Sirenen und Kalliope seinen Gesang bestaunen. ${ }^{134}$

Die ruhmreichen Taten des Achill können nur mit überragender Dichtung besungen werden - die ausserordentlichen Fähigkeiten von Held und Dichter sind zentral für die Charakterisierung der beiden. Schon bei Pseudo-Longin wird das Ausserordentliche als Bedingung des Staunens genannt:

Doch wird man bei all diesem sagen, dass für die Menschen das Nützliche und Nötige leicht zu erwerben ist, immer jedoch das Ausserordentliche bewundernswert bleibt [thaumaston ... paradoxon]. ${ }^{135}$

Bevor der Mythos der Geburt Homers in voller Länge ausgefaltet wird, werden zuerst die Heimatstadt Homers sowie drei Figuren der Mythologie, die mit ihr in Verbindung stehen, erwähnt. Theseus, der sich seiner verstorbenen Gemahlin - der Amazone Smyrna - dadurch erinnert, dass er eine Stadt (das

133 Kein Volk, kein Tag, keine zukünftige Generation / wird seinen Namen verschweigen, und auch der Neid der Antike wird ihn mit keiner Wolke bedecken. / Es wird nämlich ein Dichter geboren werden, vom heiligen Stamm der Götter, / der seinen ungeheuerlichen Taten ewiges Licht hinzufügen wird, / er wird die unbändigen Kriege der Könige erklingen lassen und mit seiner Stimme / die grauenerregenden Kriegstrompeten überdecken; die Sirene und die berühmteste / der böotischen Schwestern werden seine klingende Brust bestaunen.

134 Unter anderem hatte Silicus Italicus Kalliope staunend vor dem Gesang ihres Sohnes Orpheus beschrieben. Siehe BAusi, Commento, S. 120.

135 Longinus, Vom Erhabenen, Griechisch / Deutsch, herausgegeben und übersetzt von Otto Schönberger, Stuttgart 2008, 36, 5. Die Schrift Pseudo-Longins wird in der Folge unter Sublim. zitiert. Für Homers ausserordentlichen Geist siehe auch Ambra, V. 204. 
heutige Izmir) nach ihr benennt. ${ }^{136}$ Auf der Spitze eines Hügels weilt die vom Schmerz versteinerte Niobe, die unaufhörlich um den Tod ihrer Kinder weint. Hindurch fliesst der Fluss Meles, der dem (Trauer-)Gesang der Schwäne in den Grotten lauscht. Poliziano mythisiert die Geburtsstadt Homers zu einem Ort der unaufhörlichen Erinnerung und der Trauergesänge.

Homer wird als Sohn eines Gottes, der die Tänzerinnen des Bacchus angeleitet, den heiligen Chören der Musen geantwortet und mit Apollon gewetteifert hat, beschrieben. Heimlich hat dieser Kreitheïs geschwängert Kreitheïs gilt gemeinhin als Mutter Homers, in der griechischen Mythologie gibt es auch eine Najade unter diesem Namen (Vv. 215-218). ${ }^{137}$ Schon mit dem ersten Wimmern hat Homer das tobende Meer, tosende Winde und wilde Tiere besänftigt sowie Faune und Satyrn zum Staunen gebracht. Sogar Niobe unterbricht ihr Weinen, um dem Flötenspiel Homers zu lauschen (Vv. 220224). Die erstaunlichen Kräfte von Homers Gesang sind identisch mit jenen des Orpheus, wie sie in der Einleitung von Manto beschrieben werden (Manto, Vv. 15-20).138
Grande tamen calami reboant, grande unca remugit tibia: saepe illum vicina Faunus in umbra demirans, auris tacitus tendebat acutas, et subito puerum Satyri cinxere theatro; cum Satyrisque ferae, sed quae nil triste minentur; cumque feris silvae, sed quae alta cacumina motent, multifidaeque sacris adnutent legibus aurae. ${ }^{139}$ (Vv. 238-244)

Nicht der Dichter wird von der Natur inspiriert, sondern die Natur wird vom Dichter bewegt: Wälder und Berge bewegen sich nach den heiligen Gesetzen («sacris legibus») von Homers Gesang. Diese erstaunliche Wirkung auf die Natur findet sich noch einmal am Ende des (Lehr-)Gedichts:

${ }_{13}$ Smyrna wird nicht unumstritten von einigen Autoren, darunter Aristoteles, als Heimatstadt Homers bezeichnet. Siehe BAusi, Commento, S. 124.

137 In einigen Quellen wird Homer als Sohn von Kreitheïs und Meles beschrieben. Poliziano spielt mit unterschiedlichen Legenden und Ursprungsangaben. Mehr zu Kreitheïs findet sich auf http://www.theoi.com/Nymphe/NympheKretheis.html (Stand Arpil 2021).

138 Vgl. auch Ambra, Vv. 257-259.

139 Dennoch hallen die Pfeifen gewaltig wider, laut dröhnt die gekrümmte / Flöte: Ein Faun, ihn bestaunend aus den nahen / Schatten, spitzte seine scharfsinnigen Ohren, / und sofort umringten die Satyrn den Jungen wie im Theater; / mit den Satyrn die wilden Tiere, aber ohne unheilvolle Absichten; / und mit den Tieren die Wälder, die hohen Wipfel bewegend / und sich verneigend vor den heiligen Gesetzen der wandelbaren Lüfte. 
[...] carmine pulchro, naturamque omnem, illa ipsa mirante, figurat. ${ }^{140}$ (Vv. 573-574)

Poliziano weist mehrmals darauf hin, dass es sich beim Erzählten um Legenden handelt, die sich um Homer ranken (Vv. 213-214, 220, 229, 231). Dadurch wird der mythische Charakter zusätzlich untermauert, das Sagenhafte und Wundersame des Erzählten wird herausgestellt.

Politian recalls the Aristotelian definition of the philosopher as „philomythos,“ meaning in greek, lover of fables. Since fables consist in wonderful events, and philosophy was generated by a sense of wonder at the causes of things, there is a strong connection between the two. ${ }^{141}$

Poliziano geht noch einen Schritt weiter, wenn er, wie eben beschrieben, das Verhältnis von Natur und Dichtung umkehrt und nicht die Natur - wie bei Aristoteles -, sondern die Dichtung als Ursprung des Staunens genannt wird. ${ }^{142}$

In der Blüte seiner Jugend begann Homer, den kraftvollen Gesang der Dichter zu lieben und zu bewundern - der Ausruf «oh höchste göttliche Macht des Dichters » («oh maxima numina vatum! », V. 255) kann sowohl als Ausruf Homers oder aber als Ausruf des Erzählers verstanden werden. Figur und Erzähler treffen sich in der Bewunderung der alten Dichter.

Schon in jungen Jahren setzte sich der Furor des Achilles in Homer fest und animierte den « heiligen Dichter», ein herausragendes Werk zu konzipieren:

Iamque insana sacrum vis insertusque medullis exstimulat vatem Aeacides, iam parturit altum mens opus, et magnis animosa accingitur ausis. ${ }^{143}$ (Vv. 26o-262)

Hatten sich zuvor die Stimmen Homers und Polizianos übereinandergelegt, vermischen sich hier die Vorhaben von Achilles und Homer, denn ab «iam parturit» könnten sowohl der Dichter als auch Achilles Subjekt sein: Ein grosses Werk wird konzipiert, mutvoll wird zur grossen Tat gerüstet. Homer begehrt danach, das Antlitz Achills sehen zu können. Kraft seiner wagemutigen Evozierungs- und Imaginationskraft gelingt es ihm, die « terribilem umbram »

$140[\ldots]$ und stellt in seiner wunderbaren Dichtung / die ganze Natur (darüber staunt sie selbst) dar.

141 Greenfie LD, Humanist and Scholastic Poetics, S. 268.

142 Vgl. Met., 982b.

143 Schon durchdringt die rasende Kraft des Achilles das innerste Mark / des heiligen Dichters, schon gebiert der Geist / ein grosses Werk und rüstet sich mutig zu kühnen Taten. 
Achills „auferstehen“ zu lassen:144 Der Held erscheint ihm in der glänzenden Kriegsmontur, die er im siegreichen Kampf gegen die Trojaner trug und in der er sich aufmachte, Priamus zu besiegen (Vv. 26o-275).

Homer evoziert ein lebendiges Bild des Helden, das ihm in seiner Stärke die Sehkraft raubt (Vv. 283-284). Insbesondere von der Betrachtung von Achills Schild geht eine überwältigende Kraft aus (Vv. 279-282):

When Poliziano recounts the myth of Homer's blinding, he describes it as taking place as the poet stares at a revealed vision of the shield of Achilles - even the originary act of poetic mania concerns contemplation of a work of artifice $[. . .]^{145}$

Die Erblindung Homers wird in Überlagerung mit der Erblindung Teiresias' erzählt. ${ }^{146}$ Homer ist gelähmt und erschrocken («exterritus») von der Erscheinung, Achill aber hat Mitleid mit ihm, haucht ihm seherische Kraft ein und schenkt ihm schliesslich den mächtigen Stock des Teiresias. Dieses Bild des Achill, der sich mitleidend und liebevoll um den jungen Dichter kümmert, kontrastiert mit dem vorangehenden Bild seiner kriegerischen Erscheinung, die Schrecken und Schauer auslöste. ${ }^{147}$ Es verbinden sich in ihm - und darauffolgend in Homer - der heroische und der prophetische Aspekt der Mythologie und der Dichtung.

Nachdem Achilles Homer mit poetischem Furor erfüllt hat, hat dieser nur noch ein Ziel: Achilles, den er verehrt und bestaunt, zu besingen.

$[\ldots]$ unum ante omnis miratur amatque. ${ }^{148}$ (V. 298)

Nach diesem Vers wechselt der Text von der Beschreibung des Erweckungserlebnisses hin zur poetischen Nacherzählung der Inhalte der Ilias und der Odyssee. In dieser Nacherzählung überlagern sich nicht mehr Held (Achill) und Dichter (Homer), sondern Erzähler (Poliziano) und Dichter (Homer). Paradigmatisch dafür steht die Beschreibung von Achilles, wie er nach dem Tod von Patroklos - bewaffnet mit auserlesenen Waffen, die seine Mutter Thetis von Vulcanus hat herstellen lassen ${ }^{149}$ - das Kriegsfeld beschreitet. Diese Episode erzählt Poliziano in enger, teilweise wörtlicher Anlehnung an die Ilias.

144 Terribilis hat die Bedeutungen "schrecklich“ sowie „Ehrfurcht gebietend, ehrwürdig“, wobei Letzteres auch als „staunenswert“ interpretiert werden kann. Siehe Der neue Georges.

145 Guest, Varietas, S. 29.

146 Bausi, Commento, S. 129.

147 Vgl. die Praefatio von Manto, V. 21.

$148[\ldots]$ ihn vor allen anderen liebt und bewundert er.

149 BaUsi, Commento, S. 137. 
[...] en outre, l'ekphrasis d'Achille et son bouclier n'est rien d'autre qu'une paraphrase, voire une traduction, du texte homérique. [...] Politien se met ici en scène en tant qu'écrivain lucide créant son héros, Homère, lui-même en train de créer son personnage principal, Achille. ${ }^{150}$

Den Stellen, die nahe am Ausgangstext sind, wohnt immer auch ein kompetitives Moment inne, insofern als der Dichter seinen Vorgänger nicht nur zitieren, sondern dessen Verse weiterschreiben, umformen, übertreffen möchte. Dies zeigt sich, obwohl oder gerade weil direkt im Anschluss an die beschriebene Stelle ein Bescheidenheitstopos - zum ersten Mal in Ich-Form aufgeführt wird, dem der Fortgang der Verse widerspricht. ${ }^{151}$ Poliziano klagt, dass er nur mit Mühe und Entbehrungen von den Kämpfen und Kriegen der Götter berichten könne, schliesst an diese Aussage aber eine derart starke, bildliche Szenerie des Kriegsfeldes an, dass von Ausdrucksarmut keine Rede sein kann. ${ }^{152}$ Dieses ambivalente Spiel zwischen scheinbar grenzenloser Bewunderung des grossen Vorbildes und dem Versuch, dieses Vorbild zu übertreffen, charakterisiert die Silvae.

Die bildstarke Schilderung dient als Grundlage der Charakterisierung von Homers Sprache, die den Geist der Leser und Zuhörer energisch und heftig in ihren Bann zu ziehen vermag (V. 505). In der Oratio super Fabio Quintiliano hat Poliziano ausgeführt, dass zu bestaunen sei, wer die Reaktion des Publikums zu steuern wisse:

Quid admirabilius quam te in maxima hominum moltitudine dicentem, ita in hominum pectora mentesque irrumpere, ut et voluntates impellas quo velis atque unde velis retrahas, et affectus omnes vel hos mitiores, vel concitatiores illo emodereris, et in hominum denique animis volentibus cupientibusque domineris? ${ }^{153}$

15 O Galand-Hallyn, Les yeux de l'éloquence, S. 195. Vgl. Homer, Ilias, IXX, Vv. 373-398, dazu ebenfalls BAUsı, Commento, S. 138. Während Homer die funkelnden Waffen Achills mit denen von Helios - Hyperions Sohn - vergleicht, berichtet Poliziano davon, dass der Glanz von Achills Waffen jenen der Sonne - «Hyperionis orbem»- herausgefordert habe.

151 Einige Zeilen weiter stellt sich der Erzähler die Frage, mit welcher Stimme er den Reichtum von Homers Werken enthüllen könne (V. 467-468). Vergleichen kann er sich mit Homer nicht, denn erst aus Homers Sprache sind alle anderen Formen der Sprache hervorgegangen. Zusammenfassen kann er Homers Werke ebenso wenig, weder inhaltlich noch sprachlich, denn sie zeugen von einer nahezu unerschöpflichen Vielfalt (V. 487-496).

$15^{2}$ Siehe die Verse $376-386$.

153 Poliziano, Oratio super Fabio Quintiliano, S. 882-883. Für die Übersetzung: Polıziano, Rede des Angelo Poliziano über Fabius Quintilianus und die Silvae des Statius, S. 10o: «Was verdient höhere Bewunderung, als dass man vor einer riesigen Menschenmenge spricht und so tief in Herz und Sinn der Hörer eindringt, dass man ihren Willen überall hin 
Weniger zentral als in der Rhetorik, von der hier die Rede ist, ist in der Dichtung die Beeinflussung und Manipulation des Publikums. Vielmehr geht es ihr darum, die Zuhörer und Leser in ihren magischen Bann zu schlagen. ${ }^{154}$

Poliziano verwendet wiederum kräftige Bilder, um den Reichtum und vor allem auch das Erbe der Sprache Homers zu veranschaulichen. Bedeutend ist das berühmte Motiv des Ozeans, das bei Homer selbst, aber auch bei Quintilian, Dionysios von Halikarnassos oder Pseudo-Longin erscheint:155 Genauso wie Ozean, Vater aller Elemente, der Erde Quellen und Flüsse geschenkt hat, so hat Homer mit seinen Werken den Gelehrten die Anmut der Sprache überbracht (Vv. 476-48o). An das Bild des ozeanischen Stroms reihen sich Metaphern, die den Text als Bild oder als Gewebe («texta») ${ }^{156}$ darstellen (Vv. 483-486) und schliesslich in einem Ausruf über die Grossartigkeit Homers münden:

Quantus honor vocum, quam multis dives abundat

floribus et claris augescit lingua figuris! ${ }^{157}$ (Vv. 487-488)

Die Sprache Homers ist farbig, blumig, leuchtend, figurativ. ${ }^{158}$ An die Leuchtkraft der poetischen Sprache ist die enargeia gekoppelt, die neben der verbildlichenden Funktion auch jene der «mise en lumière » beinhaltet, gebunden an Vorstellungen der Klarheit und des Strahlens. ${ }^{159}$

Einige Stellen weiter werden die Stärke des Ausdruckes, das decorum und die variatio hervorgehoben - wiederum nicht analytisch-deskriptiv, sondern überschwänglich und voller Bewunderung (Vv. 497-589).

Dulcius eloquium nulli nec apertior unquam vis fandi fuit aut quae mentibus acrior instet: indole quemque sua pingit, sua cuique decenter

lenkt, wohin man will, und sie von allem abhält, was man nicht will, und dass man alle Gefühle, mildere wie heftigere, lenkt und schließlich Wollen und Begehren der Seelen beherrscht? »

154 GALAND, Introduction, S. 89 .

155 Galand-Hallyn, Les yeux de l'éloquence, S. 197: «Ce topos se traduit en général par une métaphore qui applique au poète grec une image tirée de son propre text (Il. XXI, 196197): celle de l'Océan, source commune de tous les cours d'eau. Denys d'Halicarnasse [...], Quintilien (X, 1, 46), l'auteur du Traité du Sublime (XIII-3) et d'autres ont célébré Homère source de tout savoir.»

156 Vgl. dazu Guest, Varietas, S. 40-41.

157 Wie gross ist der Glanz der Worte, wie viel Schmuck / überflutet die leuchtende Sprache, wie reich ist sie an eleganten Figuren!

158 Vgl. dazu auch den Vers 506: « indole quemque sua pingit [...]» Eine weitere Stelle findet sich in Manto (Vv. 321-324) in Bezug auf Vergil, wenn seine Texte mit den lebendigen Bildern, die von griechischen Frauen zur Feier Minervas auf Gewänder gestickt wurden, verglichen werden.

159 Galand-Hallyn, Les yeux de l'éloquence, S. 108. 
attribuit verba et mores; unumque tenorem semper amat, meminitque sui, scit et unde moveri et quo sit prodire tenus, fusumque gubernat arte opus, et mediis prima ac postrema revincit. Nunc teneras vocat ad lacrimas, nunc igneus iram suscitat; interdum retrahit, probat, arguit, urget; nunc nova suspendunt avidas miracula mentes, foeta bonis, ipsum utiliter celantia verum. ${ }^{160}$ (Vv. 504-514)

Wie kein anderer hat Homer es verstanden, in allen verschiedenen Stilen den richtigen Ton zu wählen, ja formbildend für diese zu wirken. Er hat die Charaktere passend gezeichnet («pingit») und stets das Werk als harmonische Einheit komponiert. Er kann Leser zu Tränen rühren, sie wütend stimmen, bisweilen zeigt er sich zurückhaltend, anerkennend, abwägend, drängend, und immer wieder gelingt es ihm, die Leser mit neuartigen, unerhörten Wundergeschichten zum Staunen zu bringen.

Homers Poesie wird auch als Ursprung allen Wissens verehrt. Seine Dichtung berichtet von den Anfängen der Welt, lehrt uns die Gesetze des Kosmos und der Natur, setzt die göttliche Wirkmacht vor Augen, beschreibt die körperliche, seelische und rationale Konstitution des Menschen und leitet die Grundsätze der Ethik sowie der Politik her (Vv. 515-555). ${ }^{161}$ Am Ende dieses Reigens stehen die Überlieferung der literarischen Genres und die Positionierung der Dichtung als Lehrmeisterin der Kunst (Vv. 556-569) - beides kulminiert in diesen Zeilen:

heroumque idem facies, et celsa potentum ora deum, variisque horrenda animalia formis, diversasque urbes positusque habitusque locorum innumeros, sensusque animorum, carmine pulchro, naturamque omnem, illa ipsa mirante, figurat. ${ }^{162}$ (Vv. 570-574)

16o Nie war jemandem eine lieblichere Redekunst gegeben oder eine reinere / Ausdruckskraft; nie hat jemand das Denken schärfer durchdrungen: / er zeichnet jeden nach seinem Charakter, jedem weist er die / angemessenen Worte und Handlungen zu; er bevorzugt / eine einheitliche Tonhöhe, bleibt sich selber treu: Er weiss, wo er beginnen / und bis wohin er fortschreiten soll, er hält sein umfangreiches Werk mit Kunstfertigkeit / zusammen und verbindet den Mittelteil mit dem, was vorher war und dem, was nachher kommt. / Einmal ruft er zärtliche Tränen hervor, ein ander mal weckt er glühend den Zorn; / bisweilen hält er zurück, anerkennt, widerlegt oder drängt voran; / manchmal werden die erwartungsvollen Gemüter mit unerhörten Wundern, die voller Tugend sind, / auf die Folter gespannt, die tiefere Wahrheit vorteilhaft verbergend.

161 Galand-Hallyn, Les yeux de l'éloquence, S. 105.

$162[\ldots]$ er zeichnet die Antlitze der Helden und die erhabenen Gesichter der mächtigen / Götter, schauerliche Tiere in unterschiedlichen Gestalten, / unterschiedliche Städte, Lagen und Gebräuche / der Orte, Empfindungen der Seele und stellt in seiner wunderbaren Dichtung / die ganze Natur (darüber staunt sie selbst) dar. 
Alles beschreibt Homer in seinem «carmine pulchro », sodass die Natur und in der Folge die gesamte antike Welt vor ihm und seinen Texten erstaunen (Vv. 575-585). Wie stark Homers Dichtung seither auf die Welt gewirkt hat, zeigt sich unter anderem darin, dass sie Alexander dem Grossen als Rat für seine Kriegszüge sowie als Vorbild seiner Triumphe diente. Die Dichtung bildet die Grundlage der Geschichte, nicht umgekehrt.

Die Errungenschaften Homers werden in einem Duktus der admiratio, gipfelnd in superlativen Ausrufen, dargebracht. Dabei erinnert das Staunen gerade in Zusammenhang mit dem Wissen, das Homer laut Poliziano zu vermitteln vermochte - an die aristotelische Bestimmung des Staunens als Anfang allen (metaphysischen) Wissens.

Weil sie sich nämlich wunderten [thaumazein], haben die Menschen zuerst wie jetzt noch zu philosophieren begonnen; sie wunderten [thaumasantes] sich anfangs über das Unerklärliche, das ihnen entgegentrat. Allmählich machten sie auf diese Weise Fortschritte und stellten sich über Grösseres Fragen [...] (So ist auch der Liebhaber von Mythen in gewisser Hinsicht ein Philosoph, setzt sich doch ein Mythos aus Wunderbarem zusammen. $)^{163}$

Mit seiner praelectio kehrt Poliziano die Reihenfolge von Staunen und Wissen um und verändert das Verhältnis von philomyhtos und philosophos. Denn gestaunt wird nicht zuerst über den Kosmos und die Natur, sondern über die Dichtung, in der die natürlichen und übernatürlichen Dinge der Welt besungen werden. Der mythos steht nicht als Erklärung des Staunens, sondern als dessen Auslöser, wobei der Mythos nicht als irrationaler von der Philosophie getrennt, sondern als deren Ursprung dargestellt wird. Dies sind Anklänge an das neuplatonische Wissensverständnis, das der Dichtung über den göttlichen furor einen hermetischen, nicht begrifflichen Zugang zu den höchsten Wahrheiten zuspricht. In Homer vereinen sich der aristotelisch-epistemologische und der poetisch-mystische Aspekt des Erkennens. ${ }^{164}$ Homer ist

[...] à la fois vates inspiré et poeta doctus, capable d'effectuer une admirable synthèse entre les révélations dispensées par Dieu et les connaissances acquises par les sciences de l'homme. ${ }^{165}$

Homer steht auch am Anfang des literarischen Werdegangs von Poliziano. Die Übersetzung von Teilen der homerischen Ilias ist Polizianos erste öffentliche literarische Tätigkeit. Genauso wie Homer damals für Poliziano als Lehrer

163 Met., 982b.

164 Bettinzoli, Daedalum iter, S. 125.

165 Galand-Hallyn, Les yeux de l'éloquence, S. 191. 
fungierte, ist Poliziano jetzt (literarischer) Lehrer seiner Studenten (vgl. Nutricia, Vv. $787-790)$.

\subsubsection{Konklusionen zu den Darstellungen Vergils und Homers}

Die beiden Poeten Vergil und Homer werden mythologisiert und in die Genealogie der Götter eingeordnet. In dieser Position wird ihnen die poetische Kraft Orpheus' zugesprochen: Alle drei erzielen mit ihren Versen erstaunliche Wirkungen.

Die Dichter schaffen mit ihren Werken (himmlische) Erinnerungsräume, die den ausserordentlichen Figuren und Personen immerwährendes Lob sichern. In der rhetorischen Haltung der admiratio - in Ausrufen der Bewunderung gegenüber den beiden Dichtern legt Poliziano seine eigene Poetik dar. In Bezug auf Vergil wird insbesondere die Vielfalt (varietas) betont, bei Homer sind es nebst der Vielfalt auch die Angemessenheit, die Originalität, die Gelehrtheit, die affektive und didaktische Wirkung, die Eleganz und die überwältigende Expressivität und Bildlichkeit seiner Sprache. Homer wird als Ursprung der poetischen Sprache und des Wissens überhaupt zur überragenden Dichterfigur emporgehoben. Sind die genannten poetologischen Faktoren in der Dichtung vorhanden, löst die Dichtung Staunen aus, überträgt das Staunen die poetische Begeisterung und verschafft dem Schreibenden sowie dem Beschriebenen immerwährenden Ruhm.

\subsubsection{Dichtung als Ursprung der Zivilisation}

Die vierte und letzte Silva ist eine Hommage an Nutricia, ${ }^{166}$ an die Amme, die als Personifikation der Dichtung auftritt. ${ }^{167}$ Anders als in den vorangehenden Silvae ist der Erzähler nicht mehr von einem Dichter inspiriert, sondern erklärt die Poesie im Allgemeinen als Inspirationsquelle und als Kraft, die den menschlichen Geist in die Höhen des gestirnten Himmels zu reissen vermag:

[...] humanas augusta Poetica mentes

siderei rapiens secum in penetralia caeli; ${ }^{168}$ (Vv. 21-22)

166 Die Verszitate in diesem Kapitel beziehen sich, wenn nicht anders vermerkt, auf Nutricia. Einen guten Einblick in die Struktur der Silva gibt GaLL, Polizians Nutricia, S. 129.

167 Nutricia ist der Plural von nutricium und bedeutet „Amme, Erzieherin“. Der frühere Titel Nutrix wurde zu Nutricia, da nutricium auch die Bedeutung von „Ammenlohn“ beinhaltet, das Gedicht ein «compenso della nutrice» ist. Siehe BAusi, Commento, S. 163. Auch Giovanni Pontano hat die Poesie im Dialog Actius als « mater foecundissima » bezeichnet, als Mutter der Religion, des Wissens, der Tugend, des Rechts, der Fürsorglichkeit und der Liebe. Siehe Pontano, Dialoge, S. 510.

$168[\ldots]$ heilige Dichtkunst, die die menschlichen Gemüter / in das Innere des gestirnten Himmels entführt. 
Die Dichtung hat den Menschen zu dem gemacht, was er heute ist: ein geheiligtes Lebewesen, das den Blick zum Himmel hebt, um mit seinem scharfen Verstand nicht nur den Weltenlauf, sondern auch dessen Schöpfer zu erahnen. Nutricia wird als Belohnung und Auszeichnung der Dichtung («praemia », V. 23) inszeniert sowie als neuer Gesang angekündigt, der von brennendem Furor zeugt (Vv. 31-32).

Er [Poliziano] definiert sie [die Poesie] als göttliches Geschenk an die Menschen, das - vergleichbar dem prometheischen Feuerraub - Kulturwerdung überhaupt erst ermöglicht. ${ }^{169}$

Bevor die Poesie sich ihrer annahm, waren die Menschen unzivilisiert und ungehobelt wie die wilden Tiere. Sie bedienten sich nicht ihres Intellekts dieser war tief verborgen und unterdrückt -, sondern lediglich ihrer Muskelkraft (V. 50). Diese Menschen kannten weder Religion, Erbarmen noch Pflichtgefühl, es gab weder Freundschaft noch Familienbande (Vv. 51-55). ${ }^{170}$ Sie hatten keine Gesetze, jeder kümmerte sich nur um sein eigenes Wohl (Vv. 55-58).

Diese ungebildeten Menschen bestaunten die Sterne, den Mond, die wiederkehrenden Jahreszeiten, vielleicht gerade weil sie deren Ursachen nicht kannten:

[...] variosque recursus

astrorum, variam Phoeben sublustris in umbra

noctis, et alternas in se redeuntibus annis

attoniti stupuere vices; insignia longum

spectabant caeli, pulchroque a lumine mundi

pendebant causarum inopes, rationis egentes. ${ }^{171}$ (Vv. 61-66)

169 Gall, Polizians Nutricia, S. 129.

170 Bei Ficino ist Orpheus die Figur, die den Menschen Menschlichkeit und Liebe bringt: «Thus, the effect of Orpheus' song is to lead man to love.» Poliziano spricht an dieser Stelle nicht von Orpheus, die Poesie hat aber die gleichen Effekte auf die Menschen, wie sie Orpheus' Gesang nachgesagt werden: die Zivilisierung des Menschen sowie die Schaffung einer menschlichen und liebenden Gesellschaft. Die Rolle der Freundschaft, der Familie und der sozialen Strukturen hat bereits Ficino von Aristoteles und den Stoikern entlehnt und es liegt nahe, dass auch Poliziano sowohl auf platonisch-orphische wie auch auf aristotelische Konzepte Bezug nimmt. Siehe Warden, Orpheus and Ficino, S. 89-91, 103 .

$171[\ldots]$ und den mannigfachen Kurs der Gestirne, / die Mondphasen, die den Schatten der Nacht leicht / erhellen, und den jährlich wiederkehrenden Wechsel der Jahreszeiten / bewunderten sie erstaunt; für lange Zeit beobachteten sie / die Zeichen des Himmels, und blieben am schönen Glanz der Erde / hängen, unwissend über die Ursachen und arm an Verständnis. 
Das erstarrte Staunen ist hier ein Ausdruck der Unwissenheit der primitiven Menschen. ${ }^{172}$ Dieser Zustand entspricht in der Ordnung des Seins, wie Ficino sie aufgestellt hat, der untersten Stufe von natura und corpus:

Die Seele, eingesperrt in die körperliche Welt, zerstreue sich in die Mannigfaltigkeit bloß körperlicher Tätigkeiten, die ihrem vegetativen Erhalt dienen. Ihre höheren Vermögen (mens, ratio) schlummerten und nur die niederen (imaginatio, sensus) seien in Tätigkeit.

Aus dieser Zerstreuung [...] könne sich die Seele durch die dichterische Begeisterung befreien, indem sie sich auf die Harmonie der Musik und Dichtung konzentriert, in dieser Konzentration die Einheit ihrer zerstreuten Teile wiederherstellt und derart in der Harmonie der Dichtung ihre eigene innere Einheit wiederfindet. ${ }^{173}$

Polizianos Verse über die primitiven Menschen sind wörtlich angelehnt an Verse der Thebais und an Lukrez' De rerum natura. ${ }^{174}$ In einer früheren Fassung des Poems hat Poliziano Vers 64 folgendermassen gebildet: « Ob admirationem philosophari coeptum. » ${ }^{175}$ In enger Anlehnung an Aristoteles' Metaphysik hat er die Verwunderung als Beginn der Philosophie und des Wissens gesetzt. In der späteren Version der Silva verschwindet diese Anlehnung an Aristoteles: Die primitiven Menschen, die mit offenem Mund dem Sonnenaufgang beiwohnten, begannen nicht von sich aus, über die Ursachen des Gesehenen nachzudenken. Dies gelang erst dank der Vermittlung der Dichtung. ${ }^{176}$ Somit ist es nicht die Philosophie, die die Menschen aus ihrer Unwissenheit führte, sondern die Poesie.

In diesem Sinne können wir Poliziano nicht in die Folge von Boccaccio stellen, der in den Genealogia Deorum Gentilium den Ursprung der Dichtung in der griechischen Kultur verortet. Seiner Meinung nach wunderten die Menschen sich über die Natur und fingen daraufhin an, über deren Ursprung und das Eine nachzudenken: Sie schafften Gott, Tempel, Priester, Opferrituale. Die Weisesten der Priester forderten nun eine herausragende und auserlesene

172 BaUsi, Commento, S. 168.

173 Volkhard Wels, Der Begriff der Dichtung in der Frühen Neuzeit, Berlin 2009, S. 203.

174 Publius Papinius Statius, Thebais, herausgegeben von Alfred Klotz und Thomas C. Klinnert, München/Leipzig 2001, IV, Vv. 282-284.

175 BAUSI, Commento, S. 170: «Vor Verwunderung begannen sie zu philosophieren.» (Übersetzung A.E.)

${ }_{17}$ In einer früheren Fassung der Silva hatte Poliziano die Dichtkunst nicht als von der Weisheit hervorgebracht bezeichnet, sondern sie mit der Weisheit gleichgesetzt (« Poetica est eloquens sapientia » / «Die Dichtkunst ist beredte Weisheit»). Mit sapientia ist nicht Wissen im aristotelischen, sondern Weisheit im neuplatonischen Sinne gemeint (ebd.). 
Form der Sprache, um über und zu Gott zu sprechen. Diese Sprache wurde von Musaios, Linos und Orpheus begründet; sie ist neuartig und erstaunlich:

Quod artificium, quoniam mirabile visum est et eo usque inauditum, ut prediximus, ab effectu vocavere poesim seu poetes, et qui composuerant poete vocati sunt; $[\ldots]^{177}$

Poliziano schliesst an die erstaunlichen Eigenschaften der antiken vates an, begründet die Dichtung aber nicht als Folgezustand, sondern als Ursprung von Religion und Zivilisation. ${ }^{178}$ Insbesondere in den antiken Kosmo- und Theogonien wurden Gott und die Welt nicht nur besungen und beschrieben, sondern erschaffen.

Die von der Poesie bekehrten Menschen staunen (stupuere) nicht mehr über die immer gleichen Naturphänomene, sondern erkennen sich im Staunen (mirari) über die Dichtung (Vv. 75-81) als Unwissende und wollen der Dichtung lauschen, bis sie das Nützliche vom Unnützen scheiden können, Recht und Gerechtigkeit kennen, den Wert der Familie kennenlernen - bis sich ihnen Sinn und Zweck ihres Menschseins offenbart (Vv. 8o-99).

Die Wirkkraft der Poesie verwandelt das Böse zum Guten, das Wilde zum Sanften:

Quippe etiam stantes dulci leo carmine captus submittit cervice iubas, roseamque dracones erecti tendunt cristam et sua sibila ponunt; ille quoque umbrarum custos, ille horror Averni, Cerberus, audita Getici testudine vatis,

177 Giovanni Boccaccio, Genealogie deorum gentilium, a cura di Vittorio Zaccaria, Milano 1998 (= Tutte le opere, vol. 7-8), S. 1406-1407: «Weil dieses Kunstwerk als erstaunliches betrachtet wurde und zu dieser Zeit ungewöhnlich war, haben sie es aufgrund seiner Wirkung - wie ich bereits erwähnt habe - poesim oder poetes genannt; und jene, die es geschaffen hatten, wurden als Poeten bezeichnet. » (Übersetzung A.E.) Zum Verhältnis von Dichtung, Philosophie und Theologie bei Boccaccio siehe den hervorragenden Artikel von JoHANNES BARTUSCHAT, «I poeti non sono le scimmie dei filosofi»: osservazioni sul rapporto tra poesia e filosofia nelle "Genealogie deorum gentilium», in: ANNA MARIA CABRini und Alfonso D'Agostino (Hgg.), Boccaccio: gli antichi e i moderni, Milano 2018, S. 47-65.

178 Warden bezieht sich auf einen anderen Ausschnitt der Genealogie deorum (V, 12) und hebt den Unterschied zwischen Boccaccio - der in der Folge des Horaz steht und der die Eloquenz als zivilisatorischen Motor definiert -, und Ficino hervor, wobei Letzterer den «skillful speaker » durch den « artist » ersetzt. Der Künstler reflektiert nicht nur, sondern kreiert - «he is < costruttore di sé〉». Die schöpferische Tätigkeit des Geistes ist mit dessen Sein und dessen Sich-Selbst-Werden identisch (vgl. Nutricia, Vv. 114-115). Poliziano ist der zweiten Position zuzuordnen. Siehe WARden, Orpheus and Ficino, S. 90. 
latratrum posuit triplicem, tria sustulit hiscens ora, novo stupidus cantu qui flexerat atram Tisiphonem, saevo lacrimas conciverat Orco; ipsum fama Iovem, cum iam Cyclopea magna tela manu quatit insurgens tonitruque coruscat horrisono et caecis miscet cava nubila flammis, ut tamen increpuit nervis et pectine pulcher Delius alternumque piae cecinere sorores, placari totumque sua diffundere mundum laetitia et subito caelum instaurare sereno. ${ }^{179}$ (Vv. 124-138)

Das Staunen über den «nov[us] [...] cantu[s]» markiert eine Verwandlung: Kerberos pausiert sein Gekläffe, als er die Lyra des thrakischen Dichters (Orpheus) vernimmt, die stürmische Hand Jupiters beruhigt sich und der Himmel hellt sich auf.

Die Stelle ist eine wörtliche Anspielung auf Vergils Georgica, auf die Poliziano bereits in der Fabula di Orfeo ${ }^{180}$ Bezug genommen hatte.

quin ipsae stupuere domus atque intima Leti Tartara caeruleosque implexae crinibus angues Eumenides, tenuitque inhians tria Cerberus ora atque Ixionii vento rota constitit orbis. (Georg., IV, Vv. 481-484) $)^{181}$

179 Denn sogar der Löwe, ergriffen vom süssen Gesang, / senkt die gesträubte Mähne, und die aufgerichteten Schlangen / strecken ihren rosigen Kamm aus und beenden ihr Zischen, / und auch der Hüter der Finsternis, der Schrecken der Unterwelt, / Kerberos, als er die Laute des thrakischen Dichters gehört hatte, / gab sein dreifaches Bellen auf und erhob seine geöffneten drei / Mäuler, erstaunt über den neuen Gesang, der die traurige / Tisiphone umgestimmt und die Tränen des grimmigen Orkus erregt hatte. / Jupiter selbst, so das Gerücht, sich erhebend und die zyklopischen Waffen / mit seiner grossen Hand schmetternd, liess heimliche Blitze mit schauerlichem / Donner aufleuchten und vermengte das umhüllende Gewölk mit unsichtbaren Flammen, / aber als der schöne Delius die Seiten seines Plektrons erklingen liess / und die frommen Schwestern abwechselnd zu singen begannen, / beruhigte er sich und verbreitete im ganzen Universum / seine Freude und sofort hellte sich der Himmel auf.

180 Siehe die Verse 187-188 der Fabula di Orfeo.

181 Vergil, Leben auf dem Lande. Bucolica - Georgica, Lateinisch / Deutsch, übersetzt, erläutert und herausgegeben von Michael von Albrecht (Bucolica) und Otto Schönberger (Georgica), Stuttgart 2013: «Ja, es staunte selbst die Behausung des Todes und die innerste Tiefe des Tartarus, die Eumeniden, deren Haar mit bläulichen Schlangen durchflochten ist, und Cerberus selbst schwieg mit dem dreifach klaffenden Rachen still, und still stand selbst Ixions Rad im Winde. » Verweise und Zitate aus der Bucolica oder der Georgica werden in der Folge mit Buc. bzw. Georg. wiedergegeben. 
Poliziano erweitert das Motiv von Kerberos Staunen über den Gesang des Orpheus, indem er es zu einem entscheidenden Motiv innerhalb des Mythos von Orpheus und Eurydike werden lässt:
Illius argutis etiam patuere querellis
Tartara, terrificis illum villosa colubris
tergemini stupuere canis latrantia monstra;
tum primum et lacrimas, invita per ora cadentes
Eumenidum, Stygii coniunx mirata tyranni,
indulsit vati Eurydicen; sed muneris usum
perdidit: heu durae nimia inclementia legis!182 (Vv. 291-297)

Die Rückkehr Eurydikes zu Orpheus wird durch das Staunen der Furien ausgelöst. Allerdings ist das Staunen über den Gesang beständiger als das kurze Glück der beiden Liebenden: Orpheus verliert Eurydike an die Unterwelt, während sein Gesang über seinen Tod hinaus Bestand hat. Letzteres wird veranschaulicht im Bild der wogenden Lyra, die ihre traurigen und wundersamen Klänge nach Orpheus Tod bezeugt.

Lesboum stupuit vulgus, cum flere natantes sponte fides atque os domini vectare cruentum vidit et heu lassis velut aspirare querelis. ${ }^{183}$ (Vv. 306-308)

Die Kraft des Gesangs überdauert den Tod des Götterdichters. Dessen Lyra weint und wimmert, als wäre sie kein Instrument, sondern die Stimme des toten Dichters, dessen Kopf sie bei sich trägt.

Das Staunen als Reaktion auf (herausragende) Dichtung zeigt sich in der letzten Silva wiederholt:

Etenim ut stellas fugere undique caelo, aurea cum radios Hyperionis exseruit fax, cernimus, et tenuem velut evanescere lunam; sic veterum illustres flagranti obscurat honores lampade Maeonides: unum quem, dia canentem

182 Bei seinen ausdrucksstarken Klagen öffnete sich auch der / Tartarus, und die schrecklichen, bellenden drei Schlangenköpfe / des Kerberos staunten über ihn; / und die Gattin des Herrschers Styx, erstaunt über die ersten Tränen / der Erinnyen, die gegen deren Willen von ihren Gesichtern flossen, / gab Eurydike dem Dichter zurück; aber er vergab die Chance / des Geschenkes: Ah, welch übergrosse Strenge des harten Gesetzes!

183 Das Volk von Lesbos erstaunte, als es die wogende Lyra / von alleine weinen sah, bei sich tragend den blutigen Kopf ihres Herrn, / und ah! als würde sie müde Klagen von sich geben. 
facta virum et saevas aequantem pectine pugnas,

obstupuit prorsusque parem confessus Apllo est. ${ }^{184}$ (Vv. 339-345)

Homer schafft es, mit der Leuchtkraft seiner Dichtung die glorreichen antiken Dichter zu überstrahlen. Vor ihm zeigt Apollon eine erstaunte Reaktion, erachtet ihn gar als ebenbürtig (V. 345). Grund seines Staunens ist die Darstellung heroischer Taten und Kriege, die in ihrem Ausdruck den realen Kriegen ebenbürtig sind.

Die letzte Silva schliesst mit einem erneuten Bezug zu Lorenzo de' Medici, der die Kurie durch seine Worte mit offenem Mund zurücklässt und mit seinen Gedichten die Aufmerksamkeit einer (unbekannten) Nymphe erregt (Vv. 728742). Mit der Dichtung erholt sich Lorenzo von den Anstrengungen der Politik, er schöpft Energie, um seine verschiedenen Tätigkeitsbereiche geschickt miteinanderzu vereinen (Vv. 766-775). Auch bei Lorenzos Sohn, PolizianosZögling, zeigen sich ausserordentliche Begabungen. Er folgt Poliziano auf Abkürzungen durch die aonischen Wälder, überholt ihn schon beinahe, sodass Poliziano zu seinem Bewunderer wird (Vv. 776-79o). Polizianos Bewunderung von Lorenzo und dessen Sohn gilt nicht ihrer Politik, sondern ihrer dichterischen Neigung wobei die Dichtung als notwendiger Gegenpol zum politischen Leben hervorgehoben wird.

\subsection{Konklusion}

Die Stanze präsentieren sich als mythologisierte Lobrede auf die Medici, die Liebe und die Kunst. Die Inspiration genauso wie die Schöpfungs- und Ausdruckskraft der Kunst werden über das Staunen charakterisiert. Dieses ist zudem handlungsauslösendes und -leitendes Element: Der Protagonist staunt erst über seine Geliebte und verfolgt sie anschliessend, dann wird er durch das Staunen über Amor, Gloria und Minerva zum Kampf im Turnier angeregt. Bewunderung und Staunen erweisen sich damit sowohl auf textueller als auch auf metatextueller Ebene als die zentralen strukturgebenden Elemente des Gedichts. Zudem manifestieren sie sich in der übergeordneten Anlage des Werkes, die sich als Bewunderung und Lob für die Familie der Medici gestaltet.

184 Genauso wie wir die Sterne vom Himmel fliehen sehen, / wenn die goldene Glut der Sonne ihre Strahlen entblösst, / und gleich wie der schwache Mond schwindet; / so verdunkelt Homer den leuchtenden Ruhm der Ahnen / mit seiner lodernden Flamme: Einzig über ihn, der die göttlichen Taten / der Helden besingt und mit seinem Gesang den wütenden Kämpfen gleichkommt, / staunte Apollon, und nur ihm gestand er Gleichwertigkeit ein. 
In den Silvae werden die poetologischen Gedanken mit Staunen konnotiert und transportiert. Im Gegensatz dazu wird die Nacherzählung der behandelten Texte ohne Äusserungen des Staunens vermittelt - ausser sie erfolgt derart lebendig und bildstark, dass sie ihr Vorbild übertrifft.

Admiratio in Bezug auf die Dichtung meint Folgendes: Die Dichtung ist aus einem wundersamen Ursprung, dem Gesang des Orpheus, hervorgegangen. Der erstaunliche Charakter seiner Gesänge hat sich auf seine Nachfolger - zuerst Achill und Homer, dann Vergil und Poliziano - übertragen. Deren Dichtungen wiederum erzeugen Staunen und Bewunderung. Die Silvae sind der Versuch, das Staunen über die antiken Texte in wiederum erstaunlicher Dichtung an die Studierenden weiterzugeben.

Das Staunen ist zudem die Grundhaltung des Dichters. In den Dienst der admiratio treten weitere rhetorische Mittel, wobei die variatio und die evidentia die wichtigsten unter ihnen darstellen.

In Poliziano finden wir keinen Widerspruch zwischen Mimesis und Furor, wie dies verschiedentlich für die Humanisten propagiert wird, ${ }^{185}$ sondern eine kreative Aneignung, Umformung und Verbindung beider Prinzipien. Kreative Mimesis zeichnet zum einen Polizianos Stil aus, zum andern versucht er, eine bestimmte Haltung - diejenige der admiratio - mimetisch in den Zuhörern hervorzurufen. Anders als die aristotelische Mimesis, die der Katharsis zudient, steht die Mimesis bei Poliziano ganz im Dienst der admiratio, die es im Leser oder Zuhörer auszulösen gilt. Diese kreative Mimesis findet statt als performative und poetische Aktion: Vom behandelten Text wird nicht berichtet, sondern er wird unmittelbar und von Neuem erzählt (geschöpft). Der Furor wird in diese Praxis integriert, indem er relativ allgemein als Inspiration gefasst wird, die in erster Linie von den poetischen Texten - nicht von den Göttern - ausströmt. Der aristotelische Begriff der Mimesis wie auch der platonische Begriff des furor poeticus werden vollständig auf die Dichtung gemünzt und erweisen sich als Anregung durch das Staunen wie auch als Ausdruck desselben.

185 Coppini, Lispirazione, S. 131. 